\title{
Response of the Asian summer Monsoons to a high-latitude thermal forcing: mechanisms and nonlinearities
}

\author{
Stefanie Talento ${ }^{1,2}$ (D) Timothy J. Osborn ${ }^{3} \cdot$ Manoj Joshi $^{3} \cdot$ Satyaban B. Ratna ${ }^{3}$ Jürg Luterbacher ${ }^{1,4,5}$
}

Received: 4 October 2019 / Accepted: 12 March 2020 / Published online: 26 March 2020

(c) The Author(s) 2020

\begin{abstract}
This study investigates mechanisms and nonlinearities in the response of the Asian Summer Monsoons (ASM) to high-latitude thermal forcings of different amplitudes. Using a suite of runs carried out with an intermediate-complexity atmospheric general circulation model, we find that the imposed forcings produce a strong precipitation response over the eastern ASM but a rather weak response over the southern ASM. The forcing also causes a precipitation dipole with wet conditions over the eastern Tibetan Plateau (TP) and dry conditions over the Bay of Bengal (BoB) and southeast Asia. A moderate increase of precipitation along the southern margin of the TP is also produced. Simulations designed to isolate the causal mechanisms show that thermodynamic interactions involving the tropical surface oceans are far less important than the water-vapour feedback for the transmission of information from the high-latitudes to the ASM. Additionally, we assess the nonlinearity of the ASM precipitation response to the forcing amplitude using a novel application of the empirical orthogonal function method. The response can be decomposed in two overlapping patterns. The first pattern represents a precipitation dipole with wet conditions over the eastern TP and dry conditions over BoB, which linearly increases with forcing amplitude becoming quasi-stationary for large forcing amplitudes (i.e. amplitudes leading to Arctic temperature anomalies larger than $10{ }^{\circ} \mathrm{C}$ ). The second pattern is associated with increased precipitation over the southeastern TP and is nonlinearly dependent on forcing, being most important for intermediate forcing amplitudes (i.e. amplitudes leading to Arctic temperature anomalies between 5 and $10^{\circ} \mathrm{C}$ ).
\end{abstract}

Keywords Asian Monsoons · High-latitude forcing $\cdot$ Nonlinear $\cdot$ Slab model

Stefanie Talento

talento@pik-potsdam.de

1 Department of Geography, Climatology, Climate Dynamics and Climate Change, Justus Liebig University of Gießen, Gießen, Germany

2 Present Address: Potsdam Institute for Climate Impact Research, Potsdam, Germany

3 Climatic Research Unit, School of Environmental Sciences, University of East Anglia, Norwich, UK

4 Center of International Development and Environmental Research, Justus Liebig University of Gießen, Gießen, Germany

5 Science and Innovation Department, World Meteorological Organization (WMO), Geneva, Switzerland

\section{Introduction}

The future pattern of global warming is expected to display a strong high-latitude signature, with observations of the last decades indicating that Arctic amplification is already taking place (Serreze et al. 2009; Collins et al. 2013). Understanding if and how high-latitude thermal anomalies might affect the global climate system is, therefore, of uttermost relevance. A large body of evidence suggest that high-latitude thermal changes do indeed impact not only the local climate but also remote regions. In particular, the Intertropical Convergence Zone (ITCZ) has been the most studied feature with research indicating that it responds to such a forcing by shifting toward the anomalously warm hemisphere (Chiang and Bitz 2005; Broccoli et al. 2006; Kang et al. 2008; Chiang and Friedman 2012; Schneider et al. 2014; Deser et al. 2015).

High-latitude thermal signals might also affect the Asian Summer Monsoons (ASM). However, the current 
understanding of this type of remote connection and the differentiation of the Monsoonal response from the ITCZ's behaviour is incomplete (Biasutti et al. 2018).

Paleoclimatic evidence from the Last Glacial Period indicates a positive correlation between temperature in the high northern latitudes and ASM strength as the abrupt warming Dansgaard-Oeschger events recorded in Greenland icecores are associated with strong ASM while the cold north Atlantic conditions of Heinrich events relate to weak ASM (Mohtadi et al. 2016; Deplazes et al. 2014; Wang et al. 2001, 2008). Nonetheless, the sparseness of the data, the difficulty in interpreting paleorecords and the presence of multiple forcings prevents robust conclusions from being drawn (Mohtadi et al. 2016). In the last millennium, records indicate a possible connection between northern high-latitudes and Asian climate, although regional differences emerge and the isolation of the extratropical signal becomes more complex. For example, tree ring width chronologies suggest that dry periods in the northeastern Tibetan Plateau (TP) coincide with NH-average cool conditions (Yang et al. 2014; $\mathrm{Li}$ et al. 2008). For the same time period, Chen et al. (2015) provide a multi-hydroproxy synthesis covering a large part of continental Asia identifying regional particularities: over eastern Monsoonal China a north-south hydroclimatic dipole acts on multi-centennial time-scales with wet north and dry south during the relatively warm $\mathrm{NH}$ conditions of the Medieval Climate Anomaly. They found the opposite (a dry north and wet south dipole in eastern Monsoonal China) during the relative cold $\mathrm{NH}$ phase known as the Little Ice Age.

Model simulations also indicate connections between the high-latitude thermal conditions and the ASM. Zhang and Delworth (2005) apply freshwater forcing in the North Atlantic of a fully coupled model and also in slab-ocean model mode. In both configurations, the forcing leads to a substantial cooling (warming) of the north (south) Atlantic and, over Asia, to decreased summer precipitation over the maritime continent and the southern tip of India. In their experiments no statistically significant anomalies are found in the rest of monsoonal Asia. Liu et al. (2009) produce a simulation of the climate of the last $21 \mathrm{kyr}$, with a fully-coupled atmosphere-ocean-sea ice-land surface model forced by transient greenhouse gas concentrations and orbitallydriven solar insolation changes. They find that during Heinrich Stadial 1 (15-17 kyr before present), when the temperatures in the north Atlantic were relatively cold, negative precipitation anomalies occur over the Bay of Bengal $(\mathrm{BoB})$ and the maritime continent, but no clear signal is found over continental Asia. Focusing on shorter time-scales, Monerie et al. (2019) analyse the simulated effects of Atlantic Multidecadal Variability (AMV) and find that positive AMV phases (in which warm conditions are found over most of the $\mathrm{NH}$ ) are associated with significant strengthening of the
ASM. Interestingly, they note that most of this response is due to the warming of the tropical Atlantic Ocean.

In general, the model simulations support the hypothesis that warm (cool) NH high-latitude conditions lead to enhanced (weakened) ASM (Zhang and Delworth 2005; Liu et al. 2009: Monerie et al. 2019). However, a more systematic analysis of the sensitivity of the ASM system to high-latitude thermal forcings, and its relationship with the ITCZ's response to such forcing, is still missing (Biasutti et al. 2018). In this study we use idealized model simulations to investigate the possible effect of high-latitude thermal forcings on the ASM. We focus on analysing the physical mechanisms and on how the effects are modified with different forcing amplitudes. For the latter purpose we introduce a novel methodology, based on the classical Empirical Orthogonal Functions (EOF; Preisendorfer 1988).

The manuscript is organized as follows. In Sect. 2 we introduce the model and the experiments. Section 3 is devoted to the results and is divided into two subsections. In Sect. 3.1 we study the physical mechanisms through focusing on the results of the experiments with the highest forcing amplitude (maximum signal to noise ratio) and we analyse the processes involved in the transmission of the information from the high-latitudes to the ASM. In Sect. 3.2 we analyse how the ASM response varies with different forcing amplitudes. Finally, in Sect. 4 we discuss the results and present the conclusions of the work.

\section{Model description and experimental design}

\subsection{Model}

We use the Abdus Salam International Centre for Theoretical Physics (ICTP) intermediate-complexity atmospheric general circulation model (AGCM; Molteni 2003; Kucharski et al. 2006). The model has a T30 horizontal resolution (roughly equivalent to a $3.75^{\circ}$ horizontal resolution) and eight vertical levels. The model includes physically-based parameterizations of large-scale condensation, shallow and deep convection, shortwave and longwave radiation, surface fluxes of momentum and energy and vertical diffusion. A Slab ocean model is coupled and a monthly-varying ocean heat-flux correction is imposed in order to keep the simulated SST close to present-day conditions. This heat-flux correction represents the effects of the oceanic circulation on the SST and is the same for all the runs. Thus, we assume that the oceanic circulation does not change in any of our experiments. The model assumes persistence of the seaice fraction. Over land, a slab model is also implemented. Present-day boundary surface conditions, orbital parameters and greenhouse gases concentrations are used as forcings 
and kept constant through all the experiments. In spite of its simplified physics approach and coarse resolution the model is successful in reproducing large-scale climatic features (both in terms of mean patterns and variability) with a performance comparable to the one of state-of-the-art models (Kucharski et al. 2013). The ICTP-AGCM has been used in research to study several topics, in particular tropical-extratropical teleconnections and Monsoon variability (Kucharski et al. 2013).
The simulated climatology of June-July-August (JJA) precipitation and near-surface winds (as simulated in a Control run of the AGCM coupled to the slab ocean model) are presented in Fig. 1, together with observational 1979-2018 analogous from NCEP-NCAR (Kalnay et al. 1996) and ERA5 (Copernicus Climate Change 2017) Reanalysis products. The model reasonably reproduces the main largescale features of monsoonal precipitation and circulation, although with significant biases expected for an intermediate

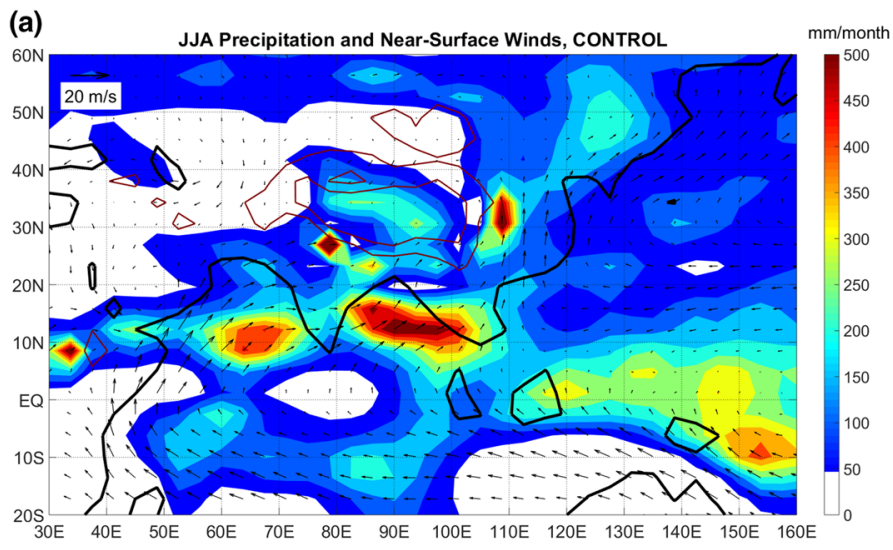

(b)

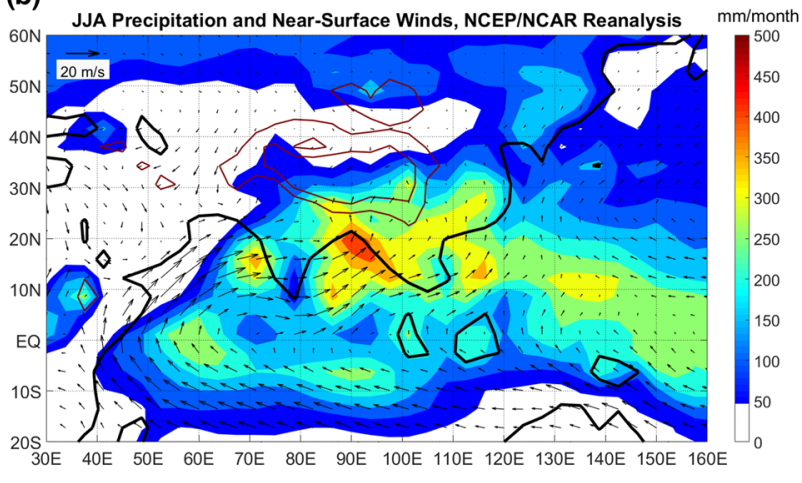

(c)

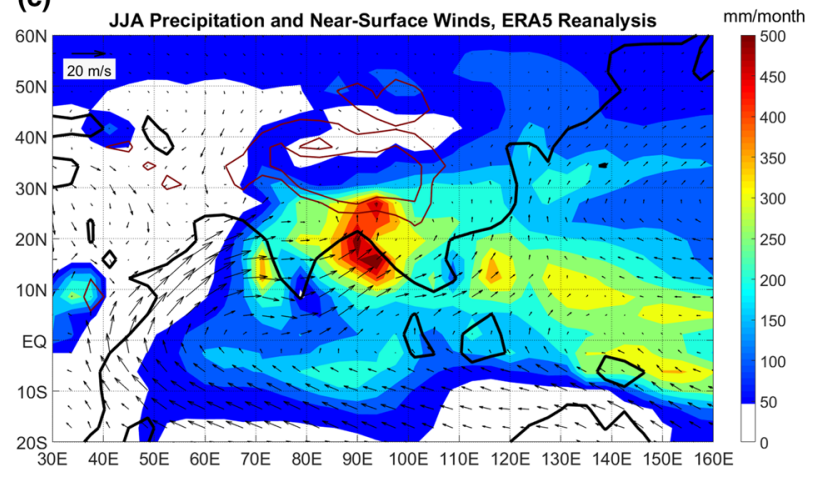

Fig. 1 a JJA precipitation ( $\mathrm{mm} / \mathrm{month})$ and near-surface winds $(\mathrm{m} / \mathrm{s})$ simulated in the Control run globalslab_0. b as a for the NCEPNCAR Reanalysis product 1979-2018 (Kalnay et al. 1996; interpolated to the model grid). c As a for the ERA5 Reanalysis product 1979-2018 (Copernicus Climate Change 2017; interpolated to the (d)
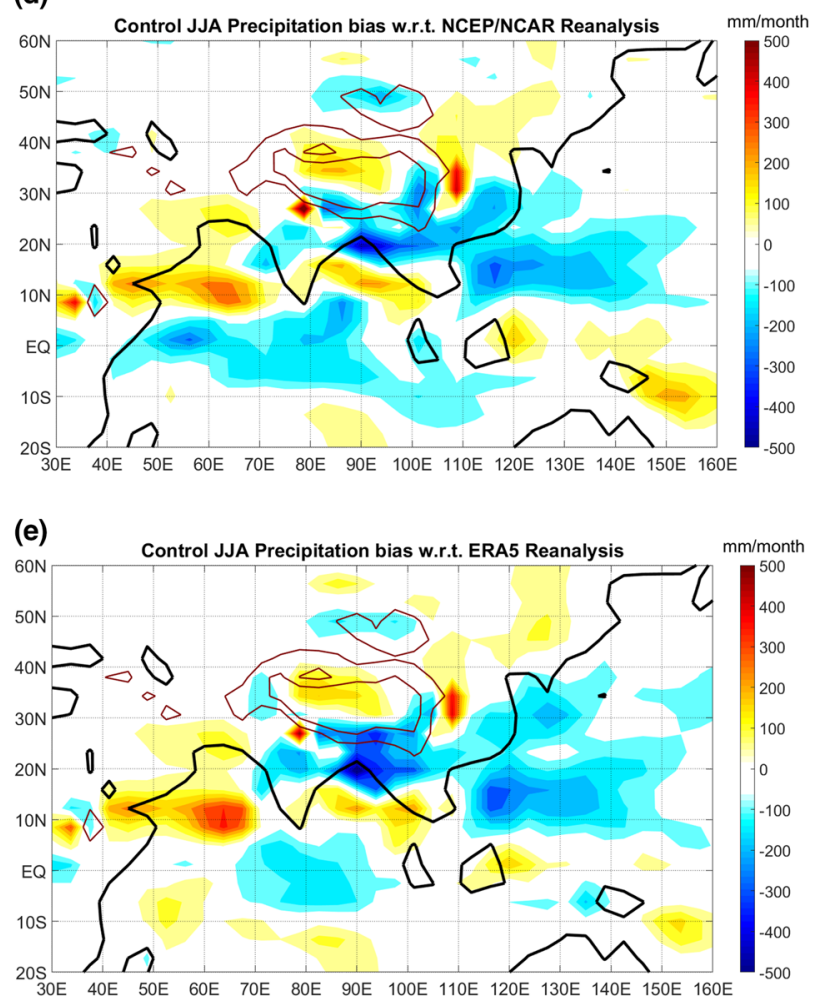

model grid). d JJA Precipitation in the Control run globalslab_0 minus precipitation from NCEP-NCAR Reanalysis. e Same as $\mathbf{d}$, for the ERA5 Reanalysis. The coast contours are the ones in the model land-sea mask and the dark red lines indicate the 1500 and $3000 \mathrm{~m}$ elevation contours also in the model 
complexity model. While the model is successful in reproducing the area where precipitation exceeds $50 \mathrm{~mm} / \mathrm{month}$ and the relative maxima on the southern and eastern flanks of the TP, it overestimates rainfall over $\mathrm{BoB}$ and the Arabian Sea and underestimates it in eastern China. Coarse model resolution accounts for the lack of precipitation maxima over western India and Myanmar as the Western Ghats and Arakan mountains are absent in the model orography. The simulated Somali jet over the Arabian Sea and anti-cyclonic circulation around the subtropical High in the western Pacific Ocean are in good agreement with both reanalysis products (Fig. 1). Noting the significant discrepancies that arise in the JJA climatological precipitation pattern among the different reanalysis (and also among observational products: Kim et al. 2019; Wang et al. 2017) we consider that the model reproduces the ASM regimes in an adequate manner.

\subsection{Experimental design}

Three different model configurations are implemented in order to better understand the mechanisms mediating in the transmission of information from high latitudes to the ASMs. In particular, the roles of the tropical ocean SSTs and water-vapour feedback will be analysed. In the first configuration (experiment name: globalslab_a, with parameter $a$ defined later), the AGCM is coupled to the slab ocean model globally. In the second configuration (experiment name: extropslab_a), the tropical $\left(30^{\circ} \mathrm{S}-30^{\circ} \mathrm{N}\right) \mathrm{SST}$ are kept fixed (with a prescribed annual cycle), while the slab ocean model is applied elsewhere. In this setting, the prescribed tropical SSTs are the monthly means obtained from a Control run with the global application of the slab ocean model. In the third configuration (experiment name: extropslabWV_a), an additional constraint of fixed water vapor greenhouse effect is incorporated. This last configuration is obtained by intervening in the model's clear-sky longwave radiation scheme so that the radiative fluxes are calculated at each time step using a climatological specific humidity obtained from the Control run instead of the specific humidity calculated within the extropslabWV_a simulation itself. For each model configuration we generate a Control run (in which no forcing is applied) and perturbed runs (in which highlatitude thermal forcings are applied).

The heat-flux Base Forcing (BF) pattern (Fig. 2) consists of warming in the $\mathrm{NH}$ and cooling in the Southern Hemisphere ( $\mathrm{SH})$, in both cases poleward of $40^{\circ}$, applied only over ocean grid points and with a resulting global average forcing equal to zero. The pattern follows a sinusoidal shape maximizing (minimizing) at $65^{\circ} \mathrm{N}\left(65^{\circ} \mathrm{S}\right)$. The forcing perturbs the air-sea heat flux (with the sign convention that positive is out of the sea). This forcing signal is similar to the one used in Kang et al. (2008) and Talento and Barreiro (2016), and represents the asymmetric temperature changes that might be associated with glacial-interglacial and millennial-scale climate variability, or a warming signal that is amplified at northern high latitudes and suppressed in the southern subpolar oceans (e.g. Osborn et al. 2017).

We define the forcings $\mathrm{Fa}$ as $\mathrm{Fa}=\mathrm{a}^{*} \mathrm{BF}$, where $\mathrm{a}=0,1, \ldots$, 7 is an amplitude factor. The case $\mathrm{a}=0$ (no forcing applied) leads for each model configuration to the corresponding Control case. To run the model a forcing Fa is superposed on the background heat-flux correction field of the slab ocean model. As the same heat flux correction field is applied to all the simulations, the differences between simulations will only reflect the effect of a different forcing. In Table 1 we summarize the experiments, the first part of the name indicates the model configuration and the last part the forcing amplitude factor.

Each simulation is 40 years long. In the simulations with the highest forcing amplitudes $(a=7)$ stationary conditions are reached approximately after 10 years. As we focus only on the stationary phase, for all of the analysis we consider
Fig. 2 Heat-flux base forcing (BF) pattern $\left(\mathrm{W} / \mathrm{m}^{2}\right)$. The sign convention is positive out of sea

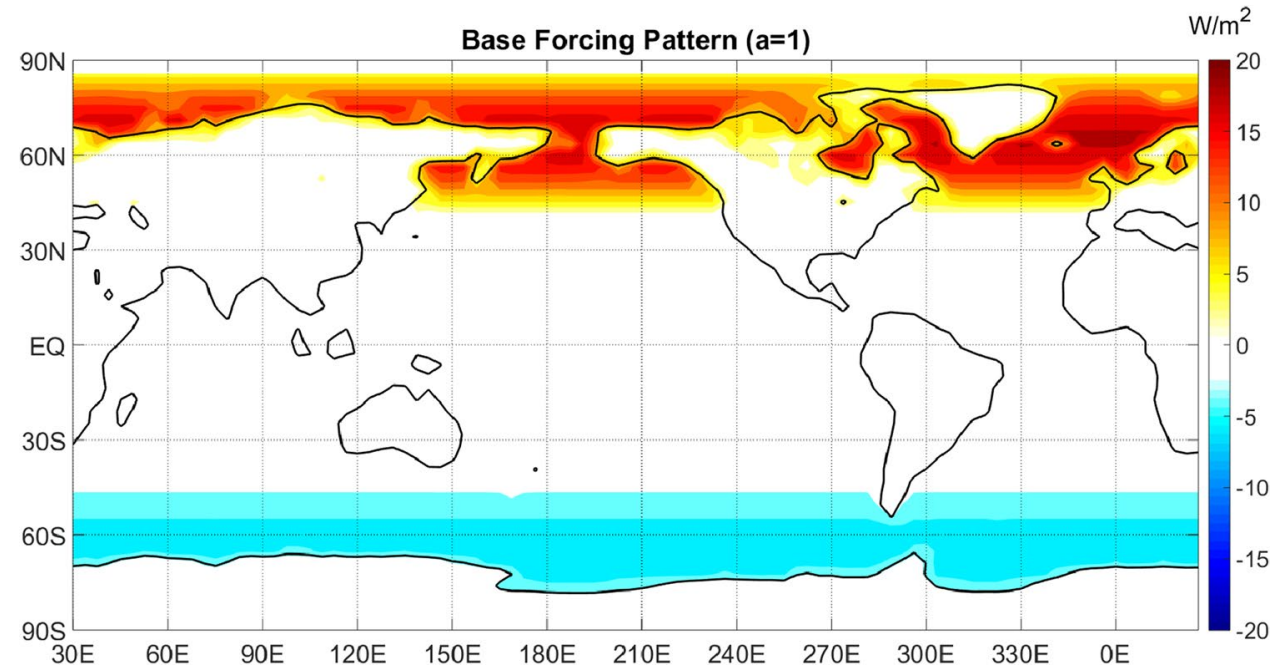


Table 1 Summary of experiments. $a=0, \ldots, 7$ is the amplitude factor of the forcing. Control cases are obtained with $\mathrm{a}=0$

\begin{tabular}{lll}
\hline Experiment Name & $\begin{array}{l}\text { Fixed tropical } \\
\text { SSTs }\end{array}$ & $\begin{array}{l}\text { Fixed water- } \\
\text { vapour green } \\
\text { house effect }\end{array}$ \\
\hline globalslab_a & No & No \\
extropslab_a & Yes & No \\
extropslabWV_a & Yes & Yes \\
\hline
\end{tabular}

the boreal summer (JJA) averages over the last 20 years of simulation. Only one member is run for each model configuration and forcing combination and, therefore, sensitivity of the results to initial conditions is not tested. To assess the statistical significance of the differences between the Control and Perturbed runs we use the Student's t-test at a 95\% confidence level. For the test, the Control (Perturbed) sample is defined as all the JJAs in the last 20 years of the Control (Perturbed) simulation.

\section{Results}

We present the results in two subsections. First, we focus on the analysis of the mechanisms involved in the transmission of information from the high-latitudes to the ASM region. Second, we analyse how a change in the magnitude of the imposed high-latitude forcing affects the ASM response.

\subsection{Asian summer Monsoon response and mechanisms}

In this subsection we focus only in the experiments with the highest forcing amplitude $(a=7)$ in order to maximise the signal-to-noise-ratio. For each model configuration, we analyse the JJA anomalies with respect to the corresponding Control case. We analyse: near-surface air temperature (NSAT), precipitation, low-level circulation (through mean sea level pressure, MSLP, and near-surface winds) and upper-level circulation (through the $200 \mathrm{hPa}$ velocity potential and divergent wind). Statistical significance is assessed through a t-test with $95 \%$ confidence level.

Figure 3 displays the JJA anomalies with respect to the Control for the experiment globalslab_7. The Asian NSAT response to the high-latitude forcing is a generalized quasizonal warming with anomalies increasing from $1{ }^{\circ} \mathrm{C}$ in the southern portion of the continent to more than $10^{\circ} \mathrm{C}$ northward of $50^{\circ} \mathrm{N}$ (Fig. 3a). The quasi-zonallity is not found over the TP where the western part warms up to $5{ }^{\circ} \mathrm{C}$ more than the eastern sector. The precipitation response (Fig. 3b) indicates that the ASM do react to the high-latitude thermal signal and that their response is not a simple shifting toward the warmer hemisphere (as it is the case for the marine ITCZ).
There is increased precipitation over the eastern slopes of the TP and all along its southern flank. At the same time, precipitation decrease is triggered over $\mathrm{BoB}$ and southeastern Asia. Note the expected northward ITCZ shift in the Pacific Ocean and also over the western Indian Ocean. Circulation at low levels (Fig. 3c) shows an anti-cyclonic anomaly centered at $10^{\circ} \mathrm{N}, 90^{\circ} \mathrm{E}$. This pattern is consistent with the decreased precipitation over $\mathrm{BoB}$ and enhanced low-level flow from the Indian Ocean inland into the southern and eastern slopes of the TP, favouring the increased precipitation in those areas. Over the Pacific, the subtropical high is weakened. Upper-level circulation anomalies (Fig. 3d, showing divergence in blue colors) clearly indicate that wind diverges over Africa and the equatorial western Pacific (in close association with the ITCZ northward shift) and it converges over BoB (in accordance with the important decrease of precipitation over this sector). Complementing the dynamical picture, moisture-flux and specific humidity anomalies are shown in Fig. 3e, f, respectively. There is a significant moisture import from the Arabic Sea and BoB converging along the southern and eastern margins of the TP in coincidence with the areas of increased precipitation. Specific humidity changes resemble the geographical pattern of NSAT anomaly, showing a generalized increase over the whole $\mathrm{NH}$, with higher anomalies toward high latitudes. Even though the pattern follows a quasi-zonal structure, the specific humidity changes along the southern and eastern TP slopes are higher than in surrounding areas to the east.

In order to understand how the ASM and ITCZ responses are related and, more specifically, to quantify the role of tropical SST anomalies in modifying the ASM response, we now analyse the experiments in which the tropical $\left(30^{\circ} \mathrm{N}-30^{\circ} \mathrm{S}\right)$ SSTs are prevented from responding to the high-latitude signal: experiment extropslab_7.

Figure 4 shows that there is still a general increase of NSAT, though the warming magnitude is reduced and NSAT anomalies are less than $1{ }^{\circ} \mathrm{C}$ equatorward of $30^{\circ} \mathrm{N}$ because SST anomalies are fixed at zero over the tropical oceans (Fig. 4a). The precipitation response (Fig. 4b) over Asia and BoB resembles the one obtained when the full slab ocean model was coupled (compare with Fig. 3b) with a slightly stronger magnitude than in the experiment globalslab_7. As expected due to the fixed tropical SST, the Pacific ITCZ response vanishes. At low levels, negative MSLP anomalies develop along the southern part of the TP, favouring increased winds from the Arabic Sea, directed eastward along the southern margin of the TP and converging over the eastern TP (Fig. 4c). At $200 \mathrm{hPa}$, an anomalous meridional circulation is evident: strong wind divergence over the eastern TP, connected via a southward flow with a convergence center over BoB (Fig. 4d). Moisture flux anomalies in this experiment (Fig. 4e) are also stronger than in the globalslab_7, and reflect that the dominant moisture 


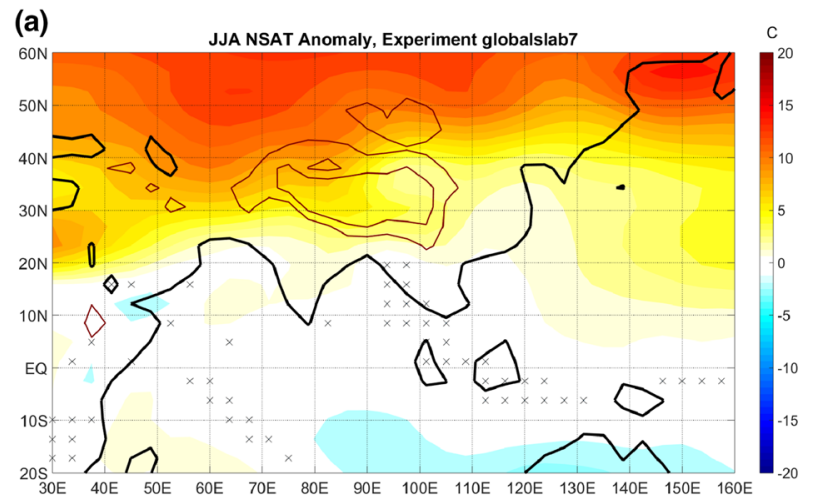

(c)

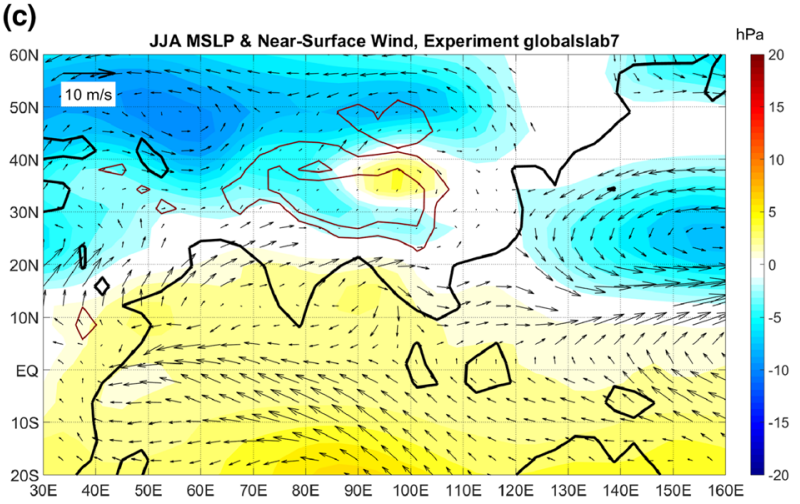

(e)

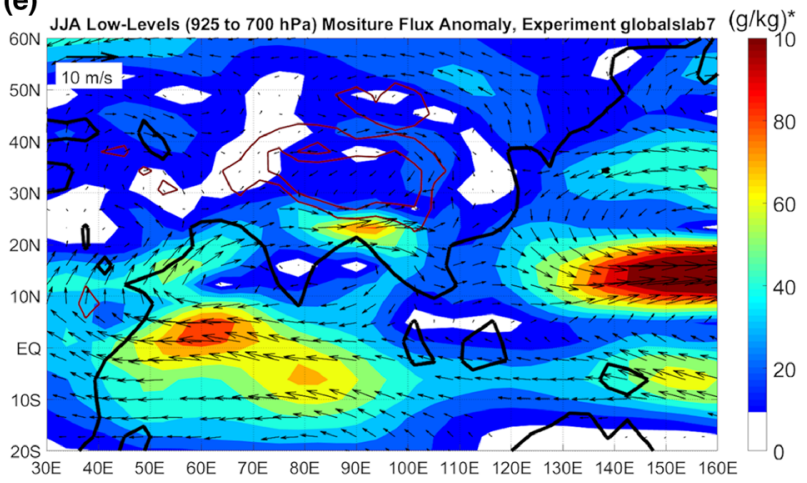

Fig. 3 globalslab_7 Experiment JJA anomalies with respect to the Control of: a NSAT $\left({ }^{\circ} \mathrm{C}\right)$, b Precipitation $(\mathrm{mm} / \mathrm{month})$, c MSLP $(\mathrm{hPa})$ and near-surface winds $(\mathrm{m} / \mathrm{s}), \mathbf{d} 200 \mathrm{hPa}$ velocity potential $\left(* 10^{6} \mathrm{~m} /\right.$ $\left.\mathrm{s}^{2}\right)$ and divergent wind $(\mathrm{m} / \mathrm{s})$, e Moisture flux $\left(\mathrm{g}^{*} \mathrm{~m} / \mathrm{kg}^{*} \mathrm{~s}\right)$ averaged over the levels $925 \mathrm{hPa}$ to $700 \mathrm{hPa}$, f Specific humidity $(\mathrm{g} / \mathrm{kg})$ aver-

transport direction is from the Arabic Sea and BoB toward the southern an eastern slopes of the TP. Specific humidity changes (Fig. 4f) are weaker than in the globalslab_7 experiment, but follow a similar geographical pattern to the seen in that configuration.

This experiment therefore indicates that the thermal interaction of the tropical SST with the high-latitude forcing signal is not very important for the response of the ASM. In particular, it highlights that the ASM can respond to the high-latitude forcing even in the absence of a marine ITCZ
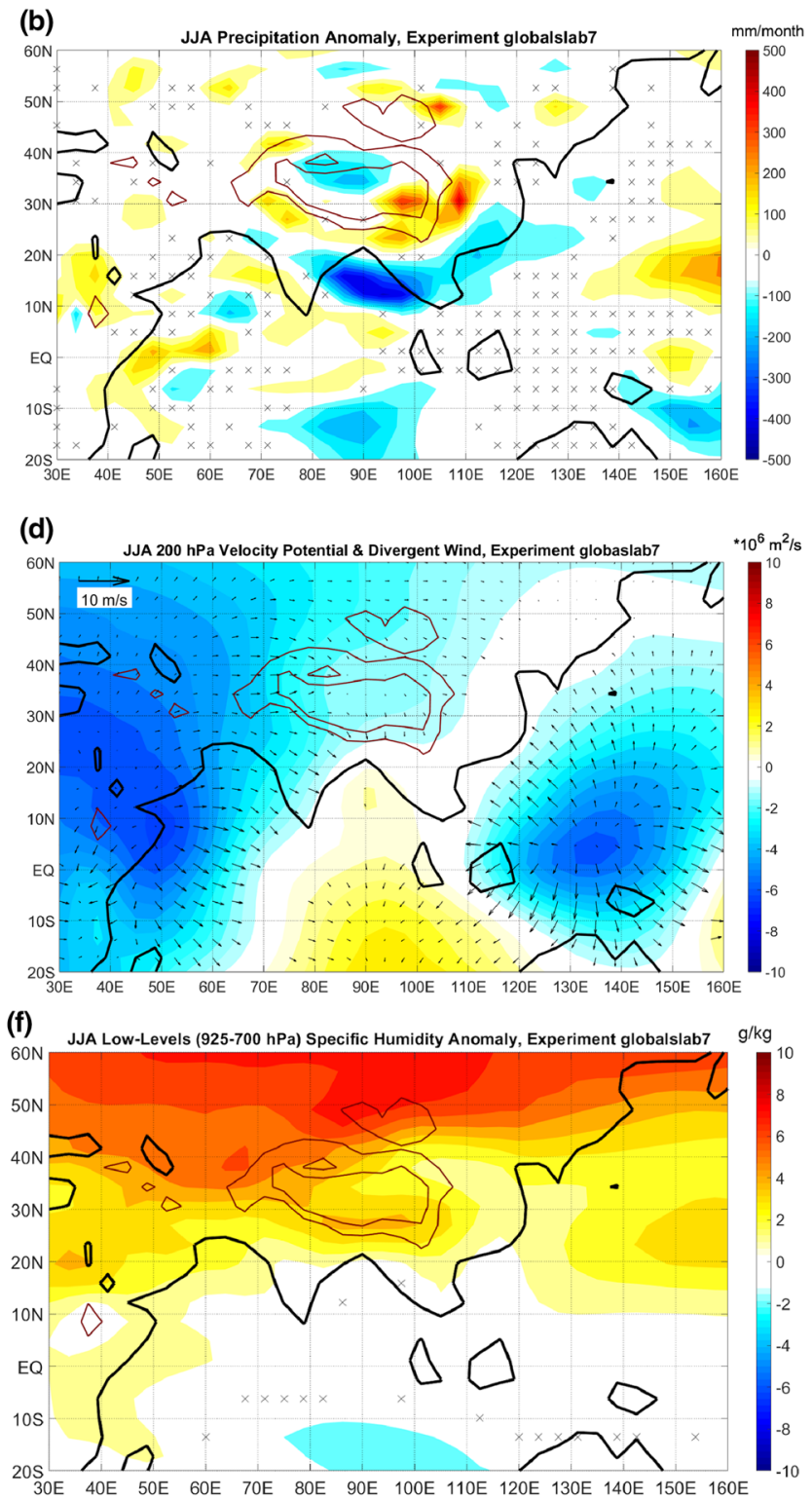

aged over the levels $925-700 \mathrm{hPa}$. Statistical significance (according to a t-test with $95 \%$ confidence level): For scalar variables hatched areas indicate non significant statistical anomalies; vector variables are only shown if the statistical significant threshold is met

response. Additional analysis of the simulation suggests that the development of negative MSLP anomalies leading to wet conditions over the southern and eastern borders of the TP is highly correlated with the pattern of NSAT increase, itself correlated with specific humidity anomalies (Fig. 4a, f). With this motivation, we designed a new experiment in which, in addition to fixed tropical SSTs, we fix the water-vapour greenhouse effect: extropslab $W V \_a$.

The results with this additional constraint are displayed in Fig. 5. The NSAT (Fig. 5a) and MSLP (Fig. 5c) 
(a)
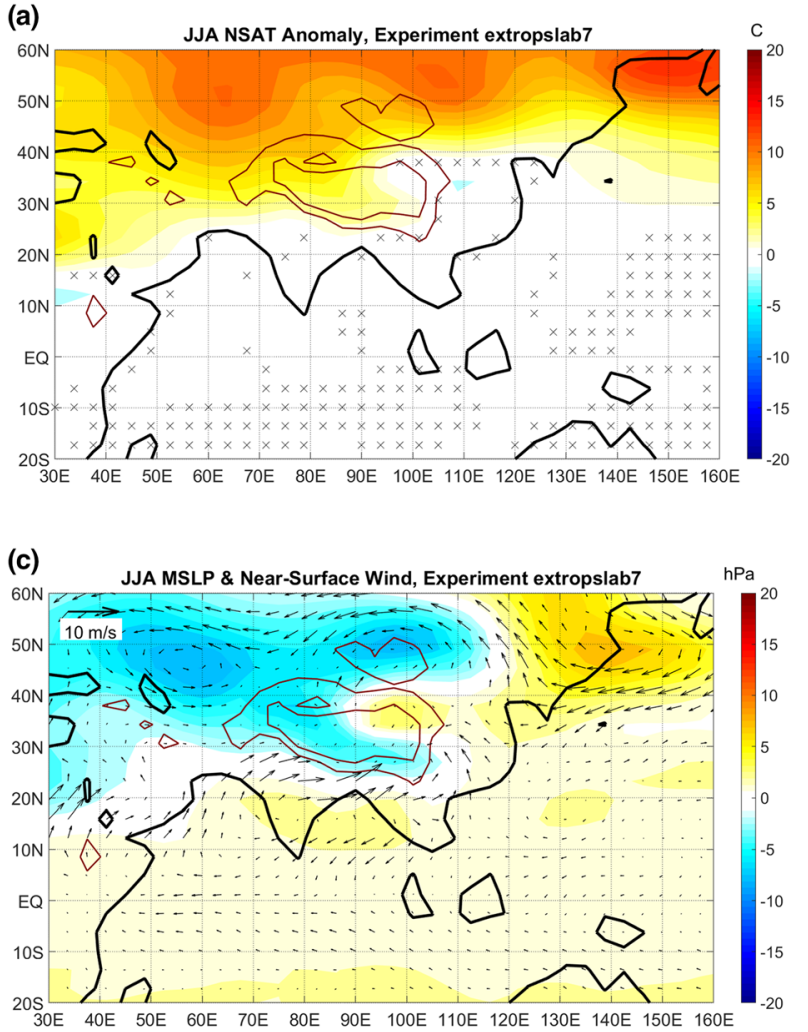

(e)

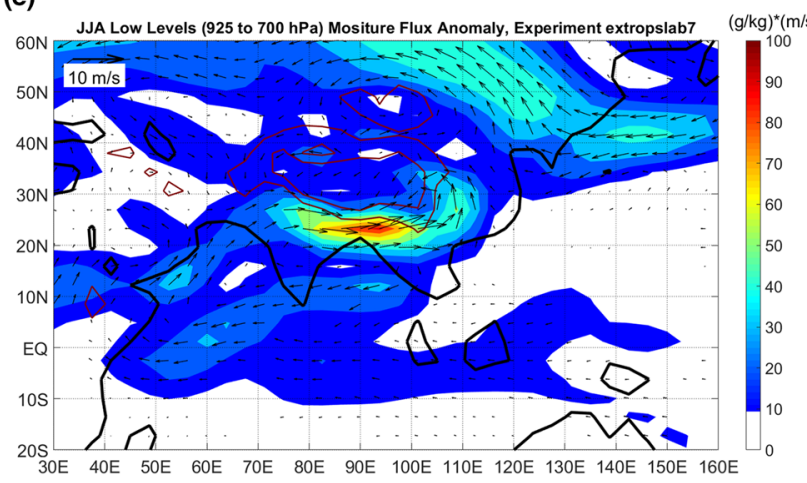

Fig. 4 Same as Fig. 3 for the experiment extropslab_7

anomalies are weaker than those from the experiment extropslab_7 and, as a consequence, the low-level wind convergence over eastern TP is reduced. The precipitation anomaly dipole (wet eastern TP-dry BoB) vanishes indicating that the water-vapour local feedback was a necessary mechanism for its development (Fig. 5b). However, we also note that positive precipitation anomalies still occur along the southern TP margin between $90^{\circ} \mathrm{E}$ and $100^{\circ} \mathrm{E}$ indicating that mechanisms other than the water-vapour feedback are also important in this area. The upper-level circulation complements the dynamical picture, consisting of an area of divergence extending from the southern border of the TP to SE Asia, without
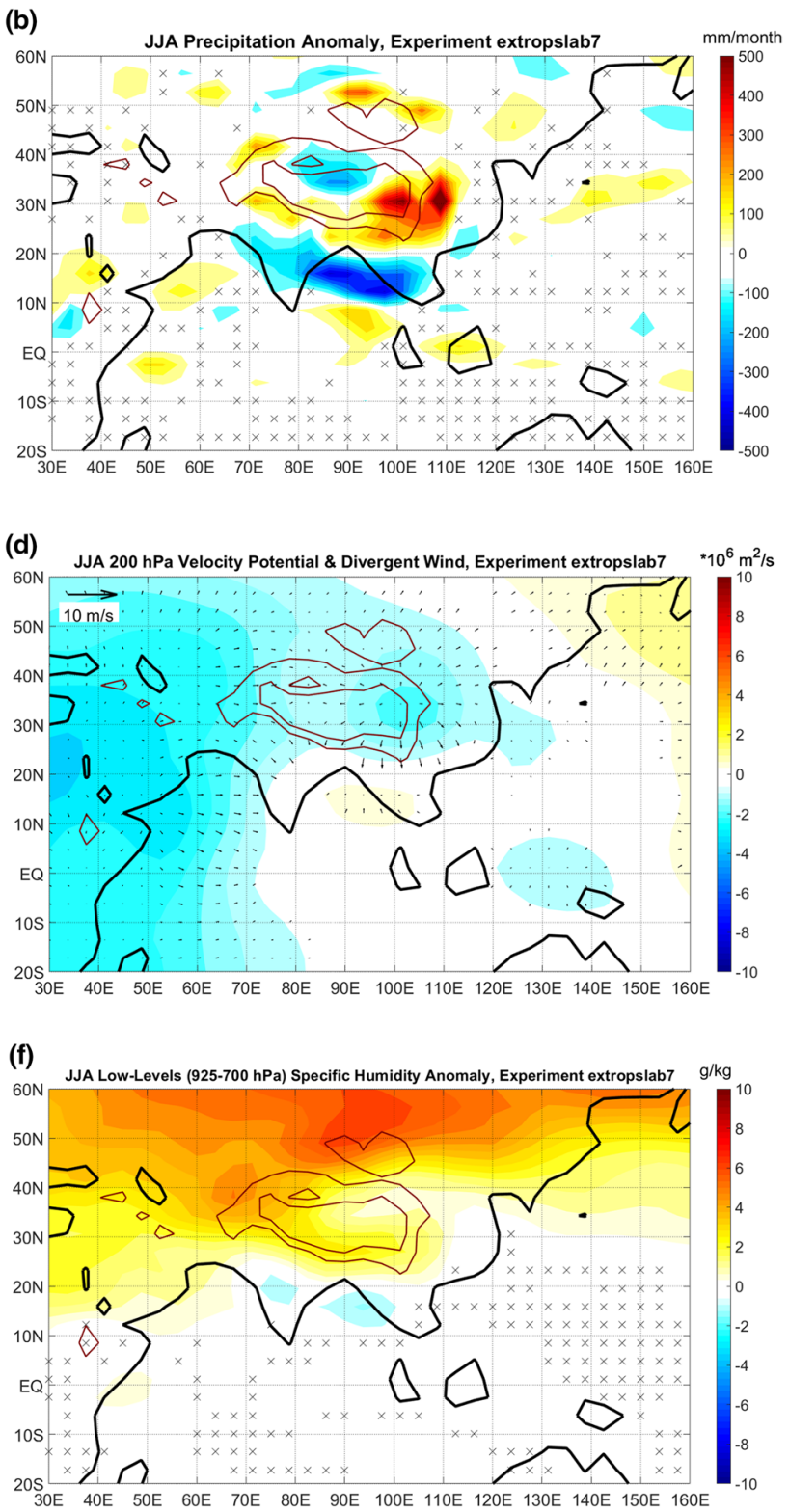

any indication of convergence over BoB (Fig. 5d). Moisture flux changes (Fig. 5e) indicate increased transport from BoB toward the southern TP margin between $90^{\circ} \mathrm{E}$ and $100^{\circ} \mathrm{E}$. For this experimental setup moisture transport changes from the Arabic Sea are not present. Finally, specific humidity changes are only of modest magnitude showing a relative maximum along the southern TP flank at $90^{\circ} \mathrm{E}, 25^{\circ} \mathrm{N}$ (Fig. 5f).

To disentangle the relative roles that the circulation and specific humidity changes play in the response of the ASMs to the forcing we analyse the moisture budget equation (Trenberth and Guillemot 1995): 

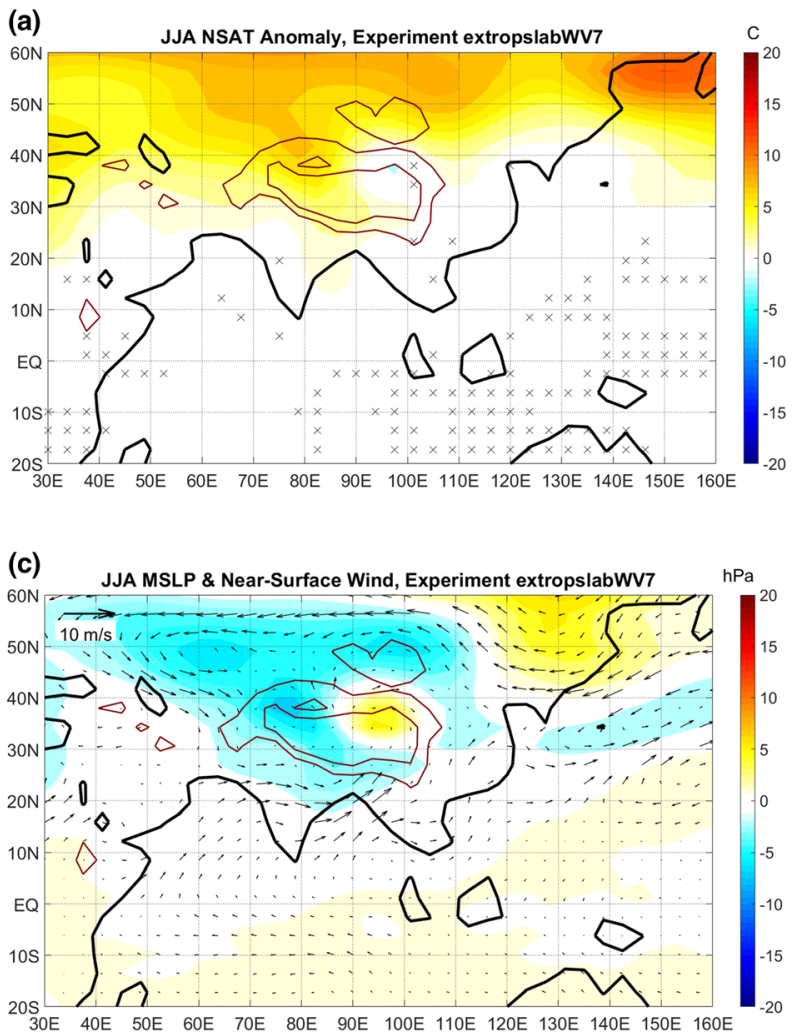

(e)

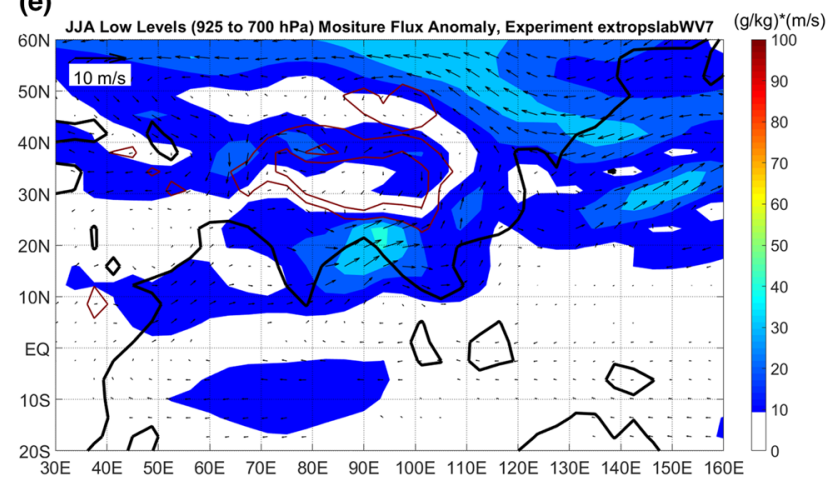

Fig. 5 Same as Fig. 3 for the experiment extropslabWV_7

$P-E=\frac{-1}{\rho g} \int_{0}^{p_{S}} \nabla \cdot\left(q v_{H}\right) d p+q_{S} v_{H S} \cdot \nabla p_{S}$

where $\mathrm{P}$ is precipitation, $\mathrm{E}$ is evaporation, $\rho$ is the density of water, $g$ is the acceleration due to gravity, $q$ is the specific humidity, $v_{H}$ is the horizontal wind velocity, $p$ is pressure and the sub-index $\mathrm{S}$ denotes values at surface level.
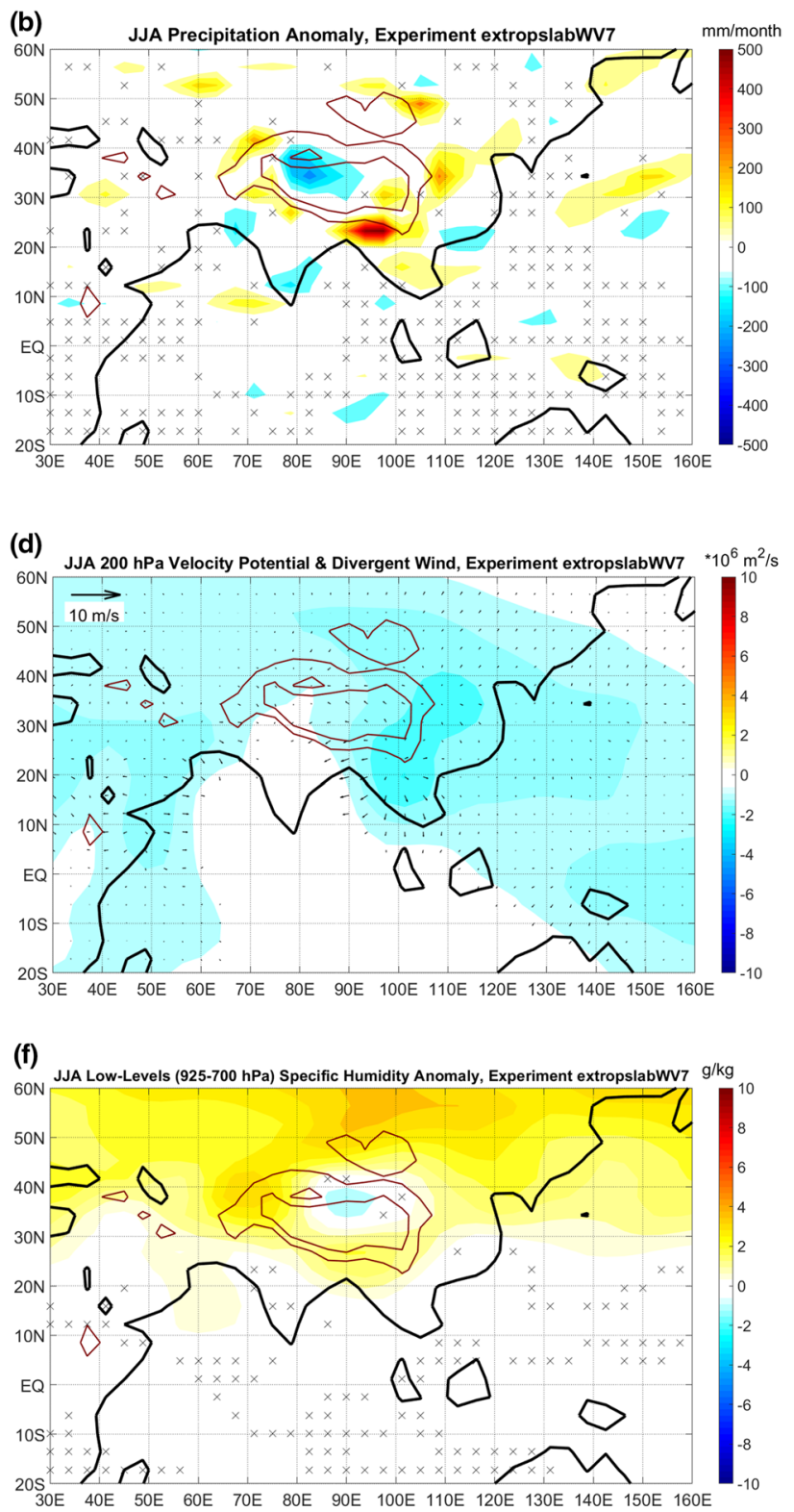

Similar to Seager et al. 2010, 2019), decomposing the fields into monthly means (denoted by overbars) and deviations from the monthly means (denoted by primes), Eq. (1) can be expressed as:

$\overline{P-E}=\frac{-1}{\rho g} \int_{0}^{p_{S}} \nabla \cdot\left(\overline{q v_{H}}\right) d p-\frac{1}{\rho g} \int_{0}^{p_{S}} \nabla \cdot\left(\overline{q^{\prime} v_{H}^{\prime}}\right) d p+q_{S} v_{H S} \cdot \nabla p_{S}$

For a given model configuration (globalslab_extraop$s l a b_{-}$or extropslabWV), the changes in the moisture budget can be expressed as: 


$$
\begin{aligned}
\delta(\overline{P-E})= & -\frac{1}{\rho g}\left[\int_{0}^{P_{s}} \nabla \cdot\left(q_{C T R L} \cdot \delta v_{H}\right)+\nabla \cdot\left(\delta q \cdot\left(v_{H}\right)_{C T R L}\right)\right. \\
& \left.+\nabla \cdot\left(\delta q . \delta v_{H}\right)+\delta \nabla \cdot\left(\overline{q^{\prime} v_{H}^{\prime}}\right) d p\right]+\delta\left[q_{S} \overrightarrow{v_{H S}} \cdot \nabla p_{S}\right]
\end{aligned}
$$

where $\delta(x)=x_{\text {Configurationa }}-x_{\text {Configuration } 0}$ denotes the difference between variable $\mathrm{x}$ in the forced run with forcing amplitude $\mathrm{a}$ and the variable $\mathrm{x}$ in the corresponding control $(\mathrm{a}=0)$. Equation (3) can be reformulated as:

$$
\begin{aligned}
\delta(\overline{P-E})= & -\frac{1}{\rho g} \int_{0}^{P_{s}} \nabla \cdot\left(q_{C T R L} \cdot \delta v_{H}\right) d p \\
& -\frac{1}{\rho g} \int_{0}^{P_{s}} \nabla \cdot\left(\delta q \cdot\left(v_{H}\right)_{C T R L}\right) d p+\text { Residual }
\end{aligned}
$$

where the Residual term includes the quadratic terms, the contributions from Transient Eddies and the surface quantities [i.g. last three terms in Eq. (3)].

The remaining terms on the right-hand side of Eq. (4) will be called Dynamic and Thermodynamic components, respectively. The Dynamic component represents the changes induced in the moisture budget by changes in the circulation only. The Thermodynamic component, in turn, represents the changes induced in the moisture budget by changes in the specific humidity only.

The Dynamic and Thermodynamic terms are first calculated, at each grid point, using monthly means and then averaged over the JJA season and area of interest. The Residual term is calculated as a residual from Eq. (4), as no daily output is available for the direct calculation of the Transient Eddies contribution.

In Fig. 6, we present the changes (with respect to Control) of the moisture budget and the corresponding Dynamic, Thermodynamic and Residual terms for the experiments globalslab_7, extropslab_7 and extrop $W V_{-} 7$. We focus only on the regions $\mathrm{BoB}$ (here defined as $82^{\circ} \mathrm{E}-110^{\circ} \mathrm{E}$, $10^{\circ} \mathrm{N}-20^{\circ} \mathrm{N}$ ) and Southeastern Tibetan Plateau (SETP; here defined as $\left.100^{\circ} \mathrm{E}-110^{\circ} \mathrm{E}, 20^{\circ} \mathrm{N}-30^{\circ} \mathrm{N}\right)$.

For the experiment globalslab_7, the negative anomaly in moisture budget over BoB is dominated by the Dynamic component, while the positive anomaly over SETP is dominated by the Thermodynamic component. Thus changes in both circulation and specific humidity are relevant for the ASMs precipitation changes.

For the experiment extropslab_7, the Dynamic term weakens considerably over BoB (as expected from the strong weakening of the circulation changes over the tropical ocean), with the balance dominated by the Residual component. Over SETP, while the Thermodynamic term still plays an important role, the Dynamic component changes sign and amplifies, becoming the dominant term. To better understand the change in the Dynamical effect over SETP it is useful to revisit Figs. 3 and 4c. They suggest that the difference in the western Pacific response between the simulations has a role: when the tropical SSTs are allowed to respond, a strong cyclonic circulation develops over the western Pacific. Over east Asia, the northerly winds associated with this cyclonic circulation oppose the southerly flow expected to develop from the north-south temperature gradient set up by the continental warming, resulting in very weak flow anomalies (weak dynamic component). In the absence of this cyclonic circulation, southerly winds are able to develop over eastern China, leading to moisture convergence over SETP (strong Dynamic component).

Finally, in the experiment extropslab $W V \_7$, the total moisture balance change and the Thermodynamic components are both negligible over BoB, while the Dynamic component is balanced out by the Residual term. Over SETP, most of the weak positive moisture budget change can be explained by the Thermodynamic component.

In summary, we find that the high-latitude thermal forcing affects the ASM precipitation. The precipitation response is characterized by a dipole with wet conditions over the eastern TP and dry ones over BoB; additional precipitation positive anomalies can also be found all along the southern margin of the TP. Regarding physical mechanisms, we investigated the relative roles of tropical SSTs and the watervapour feedback. On one hand we find that the thermal reaction of the tropical SSTs to the remote forcing signal plays a non-essential role in the ASM precipitation response, as this response still persists (and becomes even stronger over SETP) when we prevent changes in tropical SST. When the tropical SST response is absent, the land temperature changes over the Asian continent are not balanced (as no warming occurs over the tropical western Pacific Ocean), generating a stronger precipitation response over the SETP. On the other hand, we conclude that the water-vapour feedback is important for the transmission of information from the remote NH high-latitudes toward the ASM, in particular for the generation of the dipole wet eastern TP-dry BoB. Dynamical changes (due to circulation modifications only) as well as thermodynamic changes (due to specific humidity modifications only) are of importance in the precipitation response of the ASMs to the extratropical forcing. Although we focus on the results for the complete summer season (JJA), the conclusions are also, in general, valid for individual monthly means, being the anomalies in June slightly weaker than in July and August.

Drawing together the experiments and our analysis of multiple atmospheric variables, we hypothesize that the following mechanism explains the linkage between the high-latitude forcing and the ultimate ASM precipitation response. First, the forcing produces an increase of the lowlevel temperature in the NH high-latitudes (over ocean and land). This increased temperature triggers the initiation of 

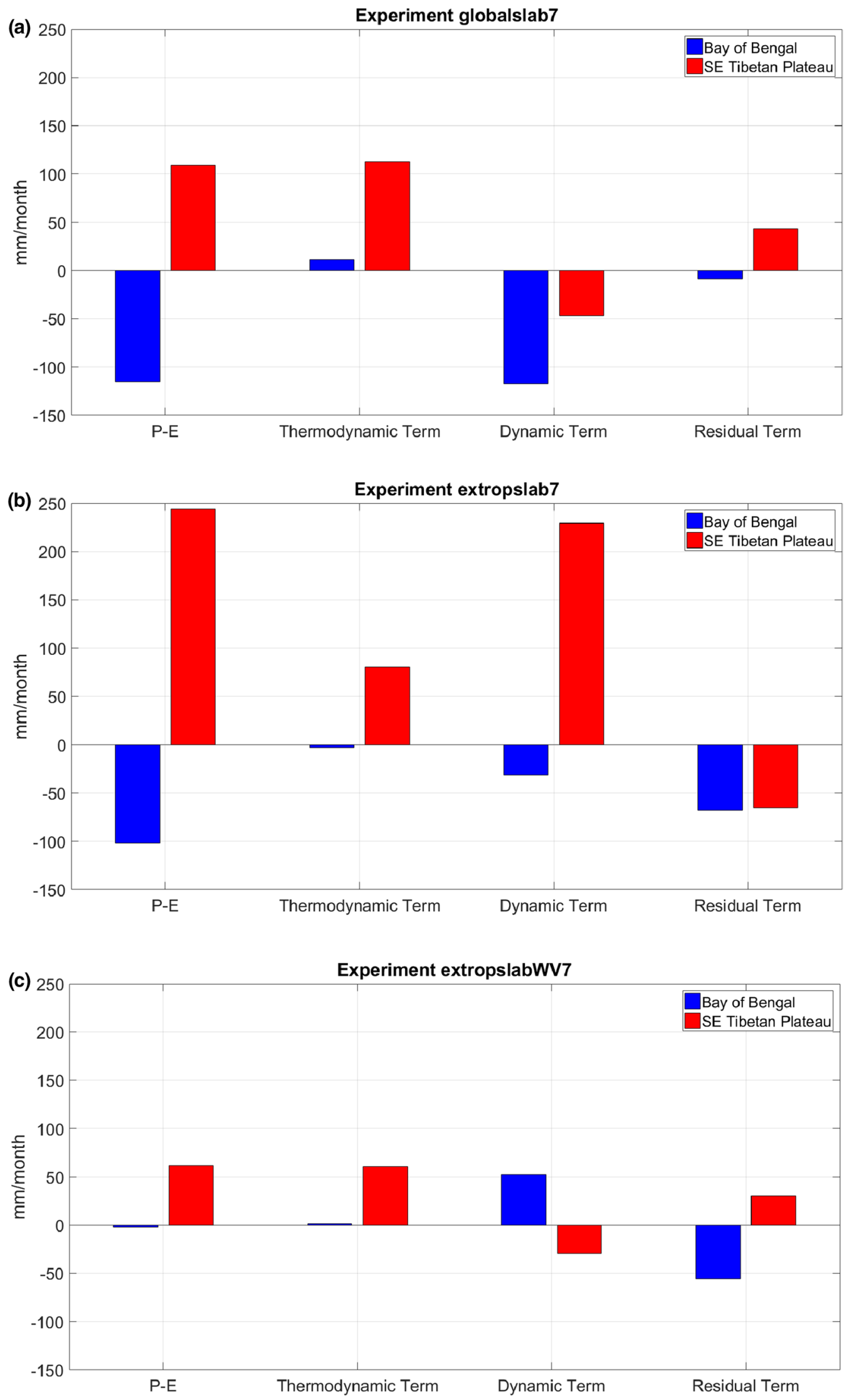
4Fig. 6 Components of the Moisture Budget in Bay of Bengal (defined here as $82^{\circ} \mathrm{E}-110^{\circ} \mathrm{E}, 10^{\circ} \mathrm{N}-20^{\circ} \mathrm{N}$ ) and Southeastern Tibetan Plateau (defined here as $100^{\circ} \mathrm{E}-110^{\circ} \mathrm{E}, 20^{\circ} \mathrm{N}-30^{\circ} \mathrm{N}$ ). a Anomalies in the Experiment globalslab_7, b Anomalies in the Experiment extropslab_7, c Anomalies in the Experiment extropslabWV_7. P-E denotes precipitation minus evaporation. Thermodynamic, dynamic and residual components are defined in Eq. (4)

a feedback with an increase of the specific humidity and radiative forcing. Second, via circulation changes, the atmospheric water-vapour anomaly is advected toward lower latitudes (in particular toward the southern and eastern margins of the TP). This increase, in turn, causes an increase in the water-vapour feedback, raising the temperatures around the southern and eastern flanks of the TP. MSLP negative anomalies are developed together with low-level wind convergence driving increased moisture flux convergence, precipitation and uplift of air. Once in upper-levels the air diverges over the eastern TP and flows southward, in an anomalous meridional circulation cell, converging over $\mathrm{BoB}$ where sinking is favoured leading, as a last stage, to a decrease in precipitation over this oceanic region.

\subsection{Nonlinearity of response}

In this section we investigate the sensitivity of the ASM to the magnitude of the imposed high-latitude forcing. We focus on the experiments in which the slab ocean model is fully coupled: globalslab_a.

For this analysis we use a novel methodology, inspired by the classical EOF Analysis (Preisendorfer 1988). In the classic EOF Analysis a certain climatic field (NSAT, precipitation, etc.) that varies with time is decomposed into spatial patterns (EOFs) and time series (Principal Components, PCs). Here, we adapt this idea but instead of analysing a variation with time, we analyse a variation with the amplitude of the forcing.

Let $\mathrm{f}(\mathrm{a}, \mathrm{l})$ be the climate variable of interest obtained in the simulation globalslab_a at location $1(1=1, \ldots, n) . \mathrm{F}_{7 \times n}$ is the matrix of dimension 7 by $n$ whose element in the position $(a, l)$ is $f(a, l)$.

Let $\mathrm{C}$ be the covariance matrix: $\mathrm{C}=\mathrm{F}^{\mathrm{t}} \mathrm{F}$.

$\mathrm{F}$ can be diagonalized in an orthonormal basis: $\mathrm{F}^{\mathrm{t}} \mathrm{F}=\mathrm{V}$ $D V^{t}$ where $D$ is a diagonal matrix whose elements are the eigenvalues of $\mathrm{C} ; \mathrm{V}$ is the matrix whose columns are the eigenvectors of $\mathrm{C}$. These eigenvectors are the EOFs and the corresponding PCs are defined as the columns of $\mathrm{F} \mathrm{V}^{\mathrm{t}}$. Each EOF (and PC) is also associated with the corresponding eigenvalue (element in the diagonal matrix $\mathrm{D}$ ), the ratio between these element and the trace of $\mathrm{D}$ is the so called explained variance of the EOF.

We apply this technique to NSAT and precipitation, independently. The spatial domain for this calculation is: EQ $-60^{\circ} \mathrm{N}, 60^{\circ} \mathrm{E}-120^{\circ} \mathrm{E}$. For each field, we focus on the first two EOFs (those explaining the highest variance).

Figure 7 shows the first two EOFs, and the associated PCs versus forcing amplitude, for NSAT. The first EOF (EOF1) explains 99\% of the variance across different forcing amplitudes and represents a generalized warming over continental Asia (with a latitudinal gradient). The associated PC1 is linear with forcing amplitude. The second EOF (EOF2) is dominated by a weak cooling over eastern Asia. Its behaviour with forcing amplitude is highly nonlinear, rising with amplitude up to a maximum at $\mathrm{a}=3$, before falling again. However, because EOF2 explains only $1 \%$ of the total variance, the overall response is clearly very close to the linear dependence on forcing strength shown by the dominant EOF1.

Results for precipitation are displayed in Fig. 8. In this case the explained variance of the first two EOFs is 75 and $16 \%$, respectively. The EOF1 spatial pattern has the precipitation dipole wet eastern $\mathrm{TP}-$ dry $\mathrm{BoB}$ that we saw in the response to the strongest forcing in the previous section. However, PC1's shows nonlinear dependence on forcing amplitude: while for $\mathrm{a}=1$ the response is almost null, for intermediate values $(a=2, \ldots, 5)$ it shows a linear strengthening with a and, finally, for high values of forcing amplitude $(a>5)$ it becomes quasi-constant. The EOF2 spatial pattern is also a dipole, but in this case the wet conditions are over the southeastern tip of the TP and the dry conditions over $\mathrm{BoB}$, has a different orientation and extends less strongly over surrounding land masses than it does in EOF1. PC2 displays also a nonlinear shape, contributing most strongly to the overall precipitation response for intermediate values of forcing amplitude $(a=2, \ldots, 5)$. The higher explained variance of EOF2 in precipitation versus temperature (and the somewhat nonlinear behavior of precipitation PC1) shows that precipitation responds far more nonlinearly to forcings than temperature, in agreement with previous work (Hawkins et al. 2014; Good et al. 2012).

Therefore, the overall picture indicates that even though the Asian temperature reacts to the forcing in a linear manner the ASM precipitation does it in a more complex way. In particular, the main response can be decomposed into two overlapping patterns associated with precipitation dipoles wet eastern TP-dry BoB and wet southeastern TP-dry $\mathrm{BoB}$. The first dipole is quasi inactive for the smallest forcing amplitude, then it follows a linear relationship with the forcing intensity, until a threshold after which its strength is almost independent of the forcing amplitude. On the other hand, the second dipole is strongest for intermediate forcing amplitudes (though it is already important for the weakest forcing case relative to the weak contribution from EOF1).

Which processes contribute to the non-linearity of the precipitation response? To gain insight we recur to the analysis of the moisture budget and its components, 
(a)

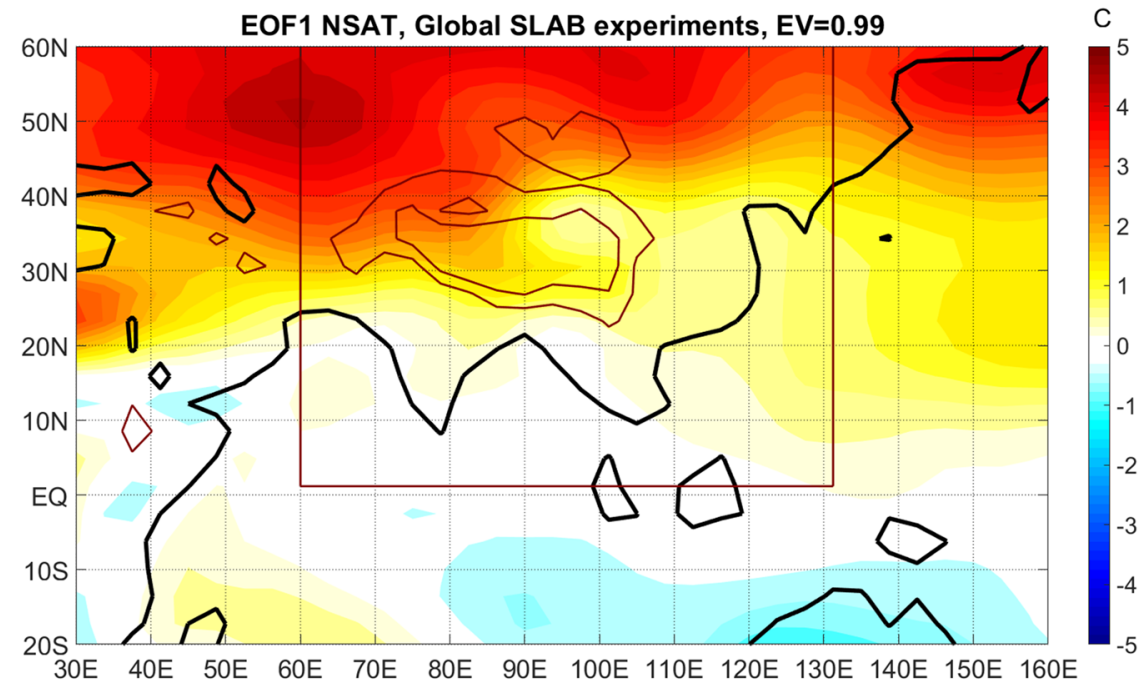

(b)
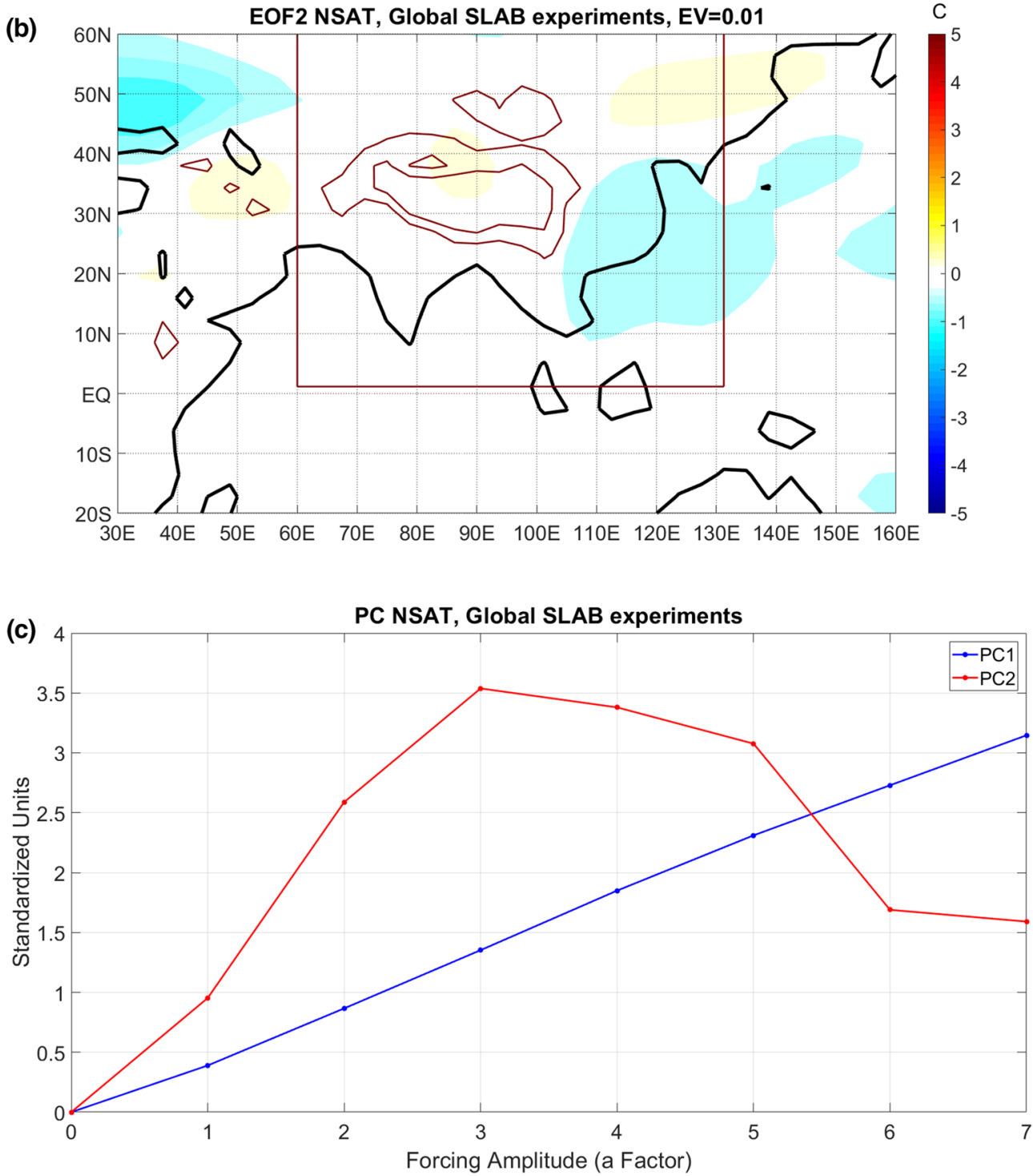
4Fig. 7 a NSAT EOF1 (C), b NSAT EOF2 (C), c NSAT PC1 and PC2, for the JJA anomalies of the experiment globalslab_7 with respect to Control. The box in panels $\mathbf{a}$ and $\mathbf{b}$ indicates the geographical domain for the EOF calculation. EV indicates the explained variance (fraction) of each EOF

according to Eq. (4). Figure 9 displays the moisture budget components (Themodynamic, Dynamic and Residual) for the regions BoB and SETP, versus forcing amplitude. It is clear that the relative contributions of the Thermodynamic, Dynamic and Residual terms to the nonlinearity in the moisture balance (and also in precipitation only) depend on the region. On one hand, for BoB the Thermodynamic component has almost no incidence (is close to zero) for all forcing amplitudes. Meanwhile, both the Dynamic and Residual components show non-linear behaviours: the dynamic effect shows almost no changes for high values of the forcing amplitude (resembling the precipitation PC1 evolution) and the residual-effect maximises (in absolute terms) for intermediate values of the forcing amplitude $(\mathrm{a}=2, \ldots, 5)$. On the other hand, for SETP non-linear changes arise in all the three terms. The Thermodynamic response is quasi-linear until $\mathrm{a}=5$, showing only small changes for higher values of the forcing amplitude, also resembling the precipitation PC1 evolution. The Dynamic response maximises for a between 5 and 6, evolving in a similar way to the precipitation PC2. The Residual has an erratic non-linear evolution, with important effects for $\mathrm{a}=1,5$ or 6 . We can then conclude that while the purely dynamical and the Residual changes explain the non-linearity in the BoB response, for SETP both the purely dynamical and the purely thermodynamic as well as the Residual changes display a complex nonlinear behaviour.

As a summary in Fig. 10 we show the precipitation response for several amplitudes of the forcing pattern. For better visualization and comparison all the results are scaled to match the magnitude of the $\mathrm{a}=7$ experiment, i.e. the precipitation anomalies of each experiment are multiplied by the scaling factor (7/a). It is also helpful to think of a certain precipitation response to the forcing with amplitude $a$ as approximately: OF2.

Precipitation anomaly(a) PC1(a)*EOF1 + PC2(a)*E

For $\mathrm{a}=1$ the main response is a dipole with centers in southeastern TP and BoB. In terms of the EOFs this can be understood because $\mathrm{PC} 1(\mathrm{a}=1)$ is almost zero and, thus, the response spatially resembles EOF2. For $a=4$ the precipitation anomaly pattern is a combination of EOFs 1 and 2, with a dipole with wet centers both in eastern TP and southeastern TP and a dry anomaly centred over BoB. Finally, for $\mathrm{a}=7$ the EOF1 is more dominant than
EOF2 and the wet precipitation anomaly over southeast TP is not so marked.

\section{Conclusions and discussion}

In a series of numerical simulations, we study the impact of a high-latitude thermal forcing on the Asian Summer Monsoons (ASM). The forcing consists of warming of the NH high-latitudes and cooling of the SH high-latitudes.

The key findings are:

1. The imposed high-latitude thermal forcing affects the ASM.

2. The strongest forcing generates an anomalous precipitation dipole response over Asia: wetter conditions over the eastern Tibetan Plateau (TP) and dryer conditions over the Bay of Bengal (BoB).

3. The effects of the forcing on the ASM can be produced even when the tropical SSTs are not allowed to change although, in that case, the precipitation response over the southeastern TP is stronger. Therefore, even though the response of the tropical SSTs to the forcing is not essential to generate an effect over ASM, it does play an opposing role with changes in the tropical ocean temperature acting to balance the temperature changes produced over land. This result also implies that the response of the ASM to a high-latitude forcing can exist even in the absence of an ITCZ response.

4. The water-vapour feedback plays an essential role, by amplifying the heating induced over the Asian land mass. This amplification, associated with an increase in specific humidity, which is in turn forced by the imposed warming, seems to be crucial for the transmission of information from the NH high-latitudes to the ASM.

5. The ASM response to the forcing is sensitive to the forcing amplitude. While forcing amplitude and Asian near surface air temperature are linearly related, the amplitude and pattern of the ASM precipitation response are nonlinearly dependent on the forcing amplitude.

6. The ASM precipitation response to the forcing can be decomposed in two overlapping patterns. The first pattern represents a precipitation dipole with wet conditions over the eastern TP and dry ones over BoB. This dipole responds weakly at first and then linearly increases with forcing amplitude until reaching quasi-stationary conditions for large forcing amplitudes (i.e. amplitudes leading to annual-mean Arctic temperature anomalies larger than $10^{\circ} \mathrm{C}$ ). The second pattern is associated with increased precipitation over the southeastern TP and is most active for intermediate forcing amplitudes (i.e. amplitudes leading to annual-mean Arctic temperature anomalies between 5 and $10^{\circ} \mathrm{C}$ ). 
Fig. 8 Same as Fig. 7 for precipitation ( $\mathrm{mm} / \mathrm{month})$ (a)

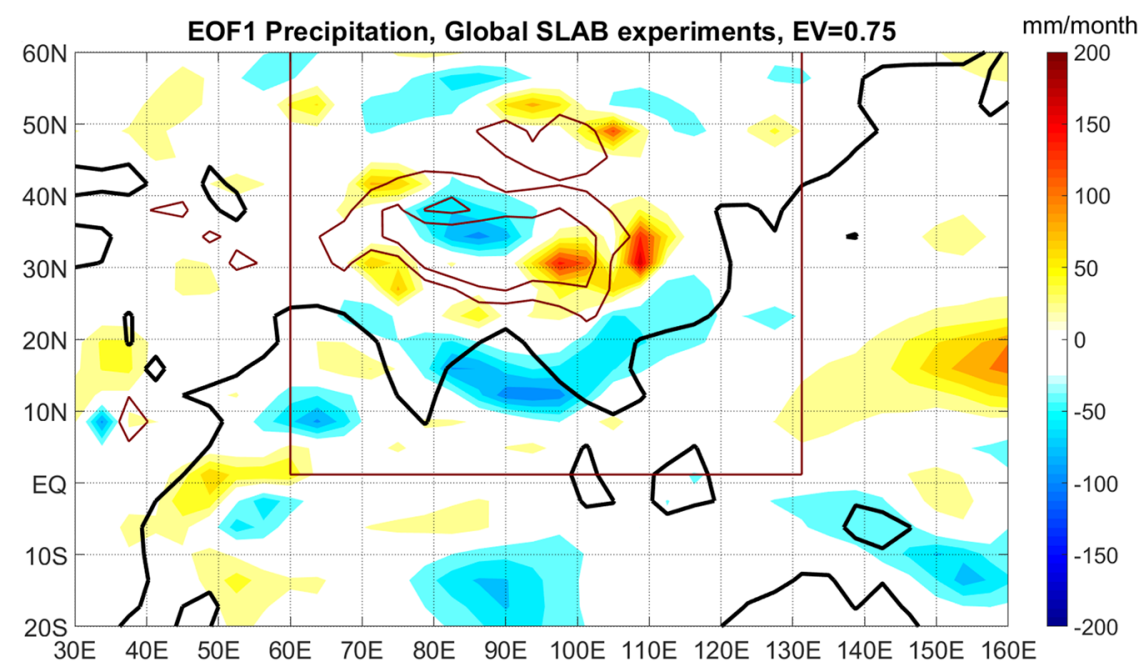

(b)

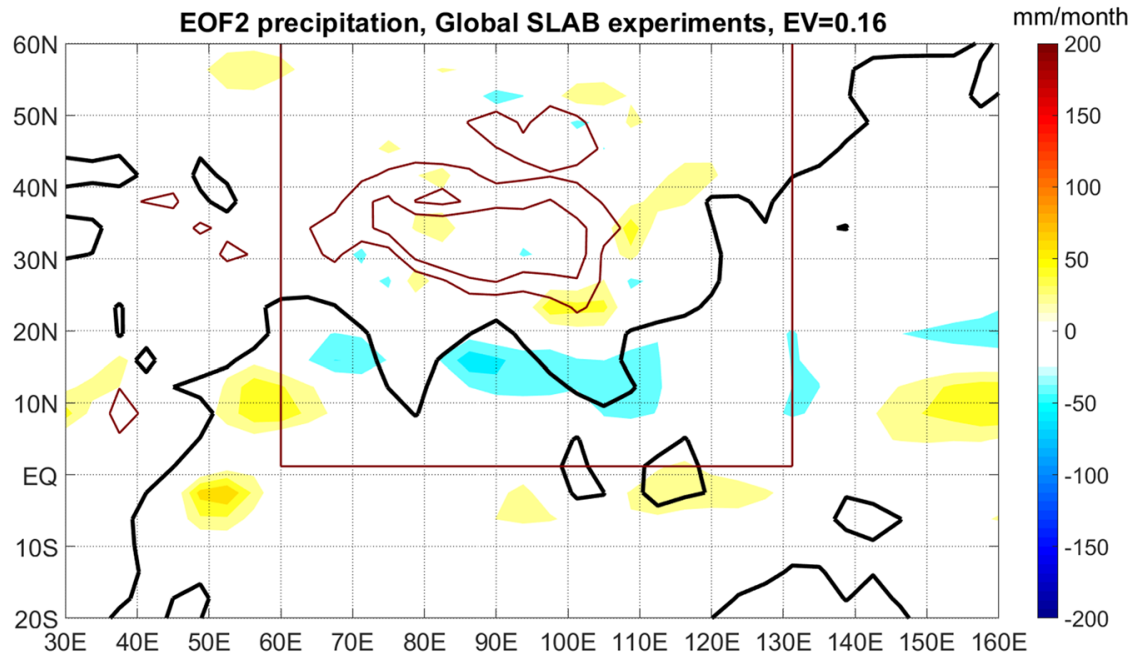

(c)

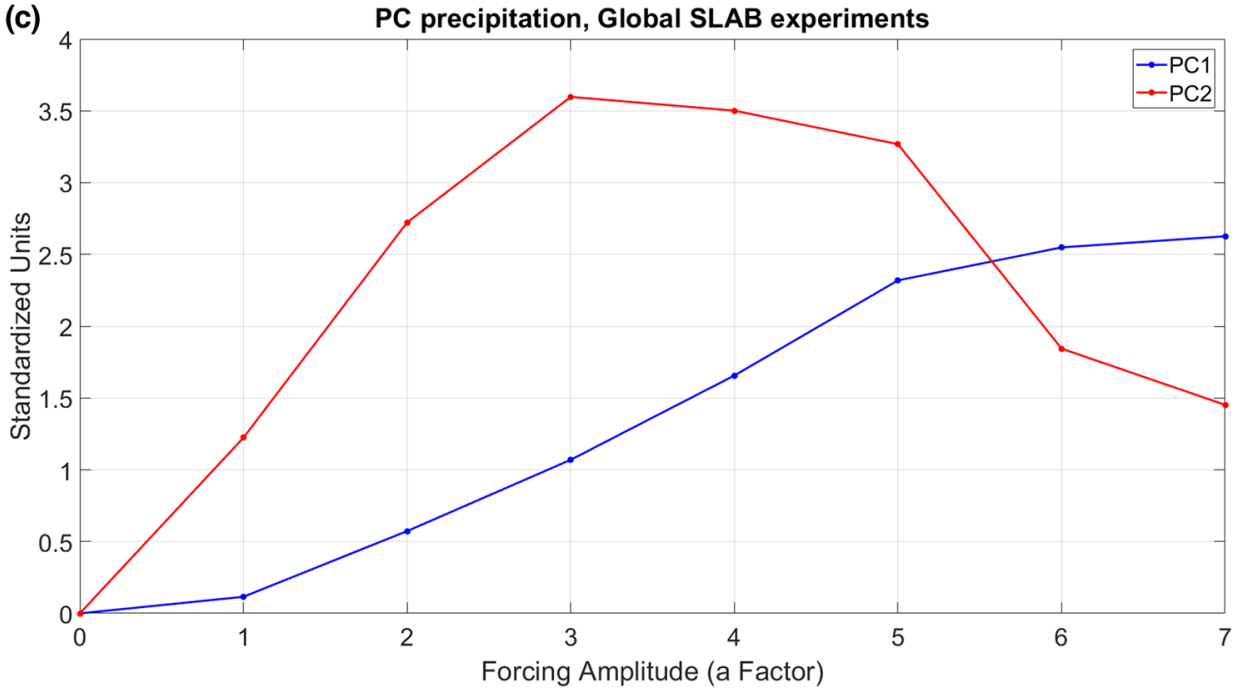


Fig. 9 Components of the Moisture Budget in Bay of Bengal (defined here $82^{\circ} \mathrm{E}-110^{\circ} \mathrm{E}$,

$10^{\circ} \mathrm{N}-20^{\circ} \mathrm{N}$ ) and Southeastern

Tibetan Plateau (defined here as $\left.100^{\circ} \mathrm{E}-110^{\circ} \mathrm{E}, 20^{\circ} \mathrm{N}-30^{\circ} \mathrm{N}\right)$ versus Forcing Amplitude (a Factor) for the experiment globalslab. a Precipitation minus evaporation, b Thermodynamic component, $\mathbf{c}$ Dynamic component and $\mathbf{d}$ Residual component, as defined in Eq. (4) (a)

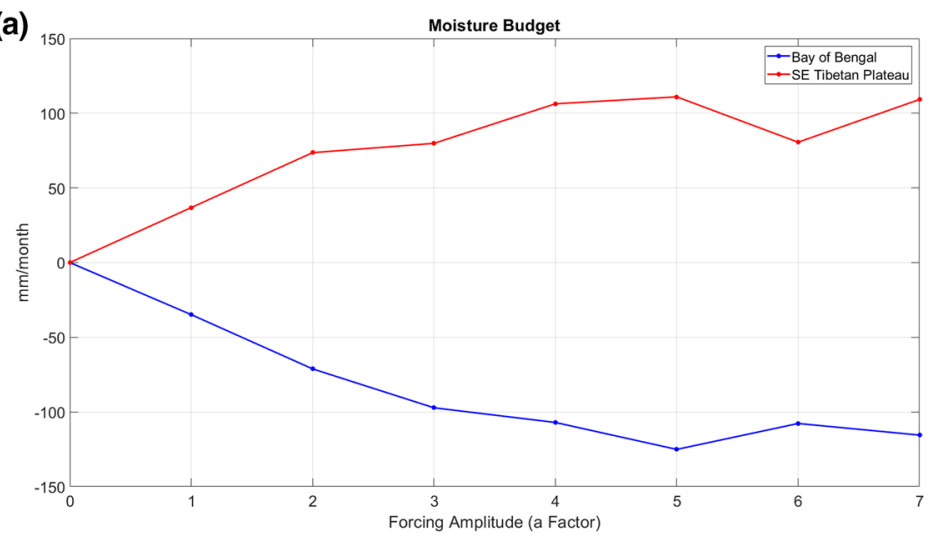

(b)

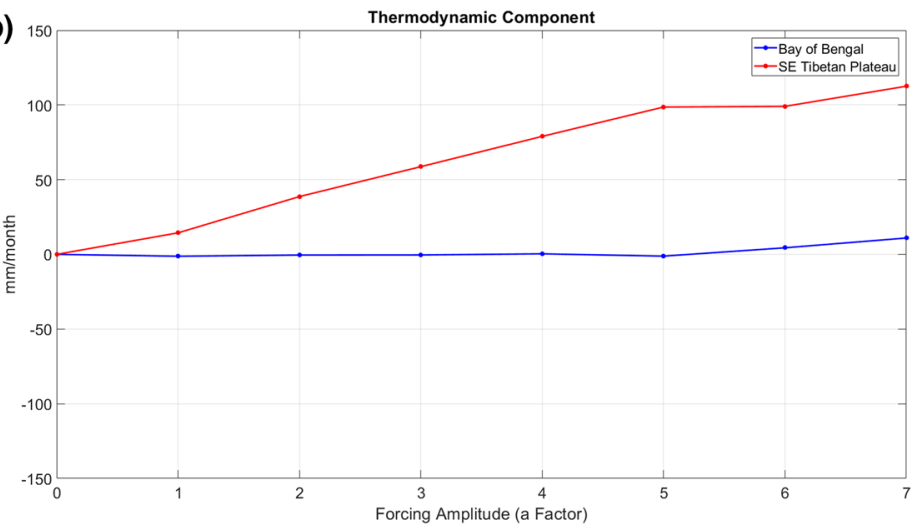

(c)

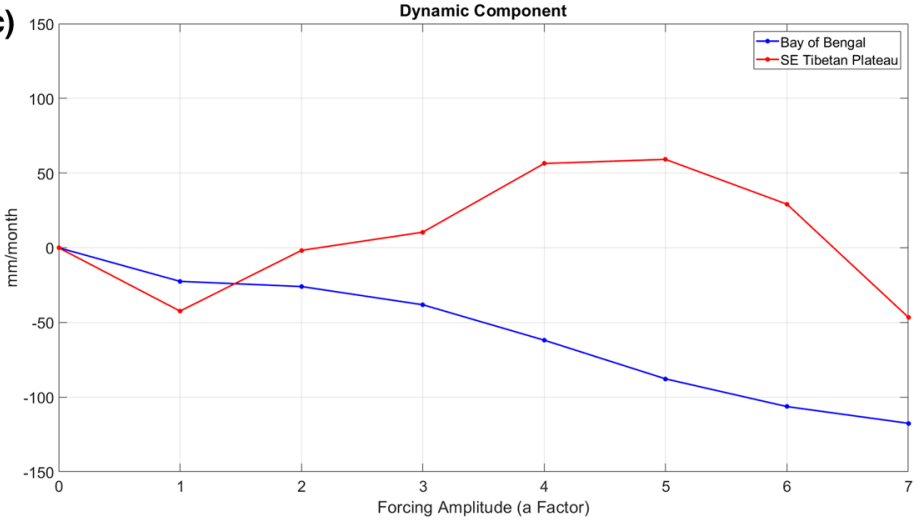

(d)

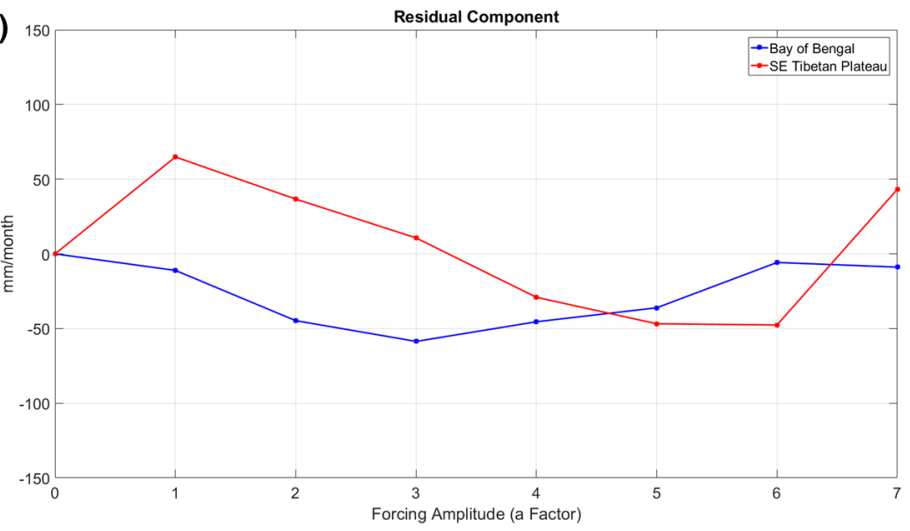


Fig. 10 JJA precipitation anomalies with respect to the Control for the Experiment globalslab_a, multiplied by the scaling factor (7/a) for: $\mathbf{a} a=1$, b a $=4, \mathrm{ca} .=7$

Hatched areas indicate non significant statistical anomalies (according to a t-test with 95\% confidence level) (a)

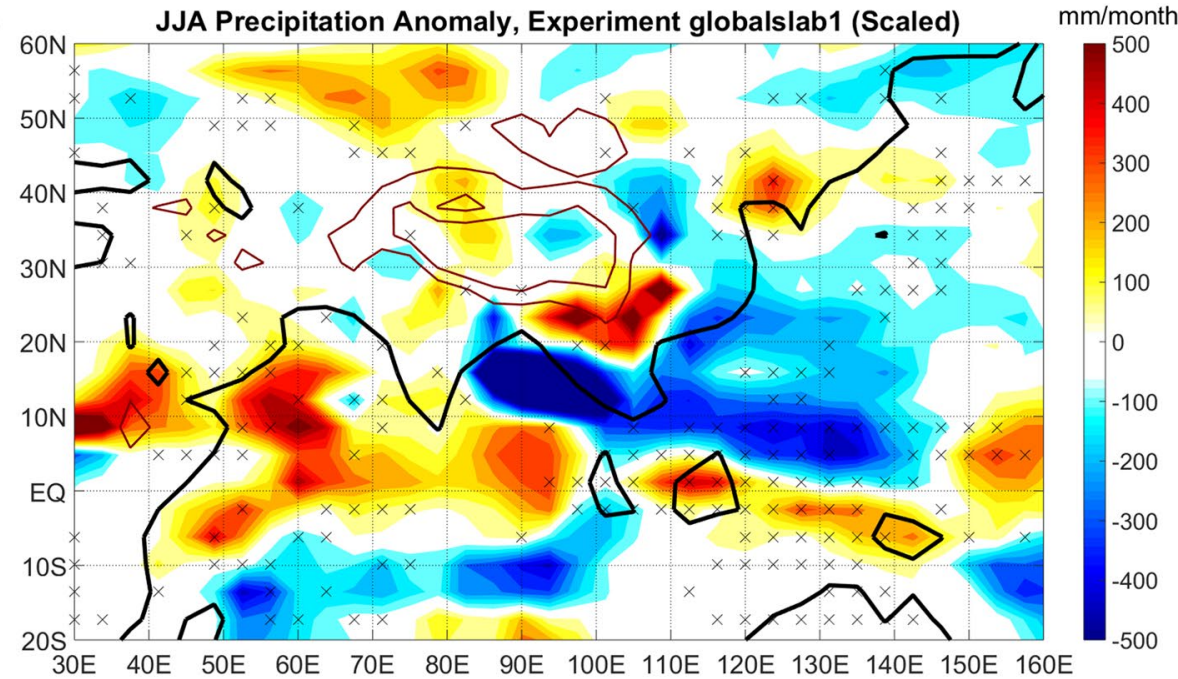

(b)

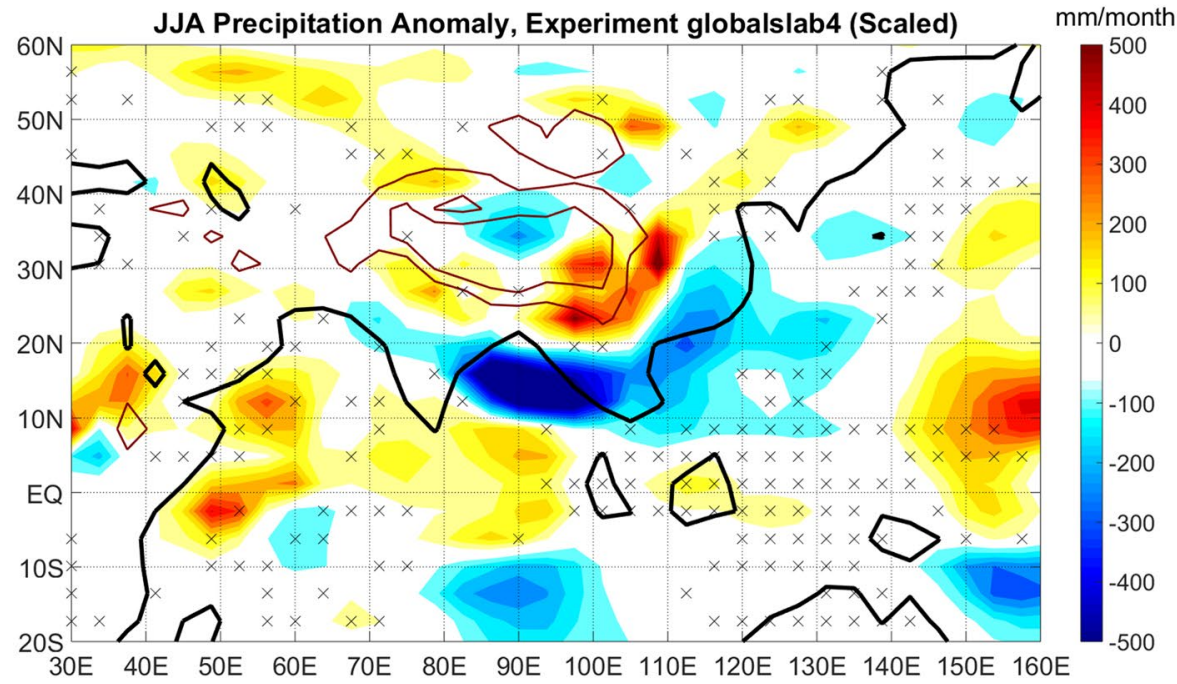

(c)

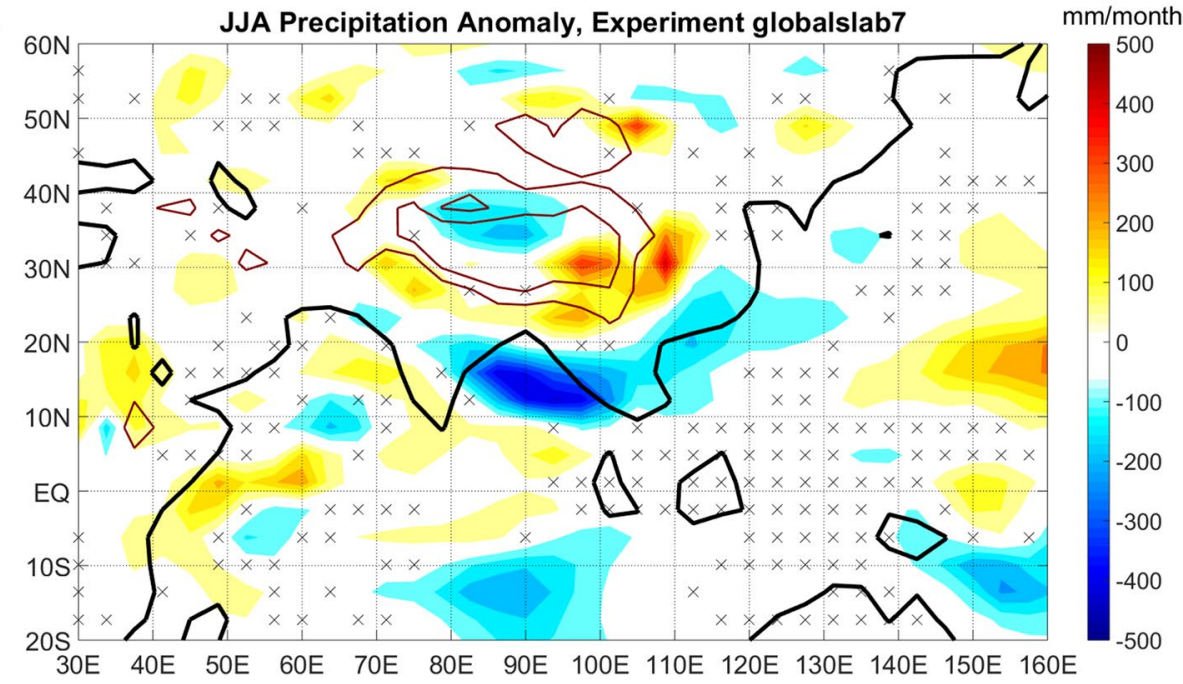


Our results are in agreement with the general hypothesis, derived from paleoproxy information and previous numerical simulations, that warmer NH high-latitudes lead to enhanced ASM. In particular, in our experiments a dipolar pattern similar to the one identified by Chen et al. (2015) in north and south eastern monsoonal China during the last millennium is evident. Moreover, the sign of the dipole is in agreement with the Chen et al. (2015) hydroclimate proxy compilation and supports the notion that warm $\mathrm{NH}$ extratropics are associated with a wet north and dry south over eastern China.

In the context of future climate change, CMIP5 projections for the end of the 21 st century place the annual-mean surface temperature gradient between the Arctic and the Tropics in the range of $1.3-5^{\circ} \mathrm{C}$ (Collins et al. 2013). In our simulations, comparable magnitudes of Arctic-Tropics gradient can be obtained with amplitude factors ranging between $\mathrm{a}=1$ and $\mathrm{a}=2$ (leading to values of the gradients between 2.7 and $5.2{ }^{\circ} \mathrm{C}$, respectively). Thus, even considering the limitations of our idealized setting, we could interpret the results as indicators of a possible increase in monsoonal precipitation over the eastern TP and along its southern margin. CMIP5 simulations, in general, project enhanced precipitation over land in all NH Monsoonal systems (Kitoh et al. 2013; Lee and Wang 2014; Seth et al. 2019), which is in line with our results.

The EOF-based methodology used here could be useful for identifying nonlinearities in the simulated responses to other forcings applied with varying amplitude. For example, pattern-scaling methods for emulating climate model projections typically rely on a single pattern linearly linked to the magnitude of global-mean warming (e.g. Osborn et al. 2016) but could be extended to use multiple patterns derived via EOF analysis in the space-forcing dimensions to better capture nonlinear climate change responses (Herger et al. 2015).

Finally, we acknowledge that the model configuration used here lacks a fully dynamic ocean model and, therefore, relevant ocean feedbacks might be missing. The results could also be model-dependent and horizontal and vertical resolution could have an important impact, thus, performing similar experiments with other models could be interesting to determine the robustness of the results.

Acknowledgements Open Access funding provided by Projekt DEAL. The authors were supported by the Belmont Forum and JPI-Climate Collaborative Research Action "INTEGRATE: An integrated datamodel study of interactions between tropical monsoons and extratropical climate variability and extremes". Funding for TJO, MJ and SBR was provided by UK NERC grant NE/P006809/1. Funding for ST and $\mathrm{JL}$ was provided by the German Bundesministerium für Bildung und Forschung grant BMBF 1LP1612A.

Open Access This article is licensed under a Creative Commons Attribution 4.0 International License, which permits use, sharing, adaptation, distribution and reproduction in any medium or format, as long as you give appropriate credit to the original author(s) and the source, provide a link to the Creative Commons licence, and indicate if changes were made. The images or other third party material in this article are included in the article's Creative Commons licence, unless indicated otherwise in a credit line to the material. If material is not included in the article's Creative Commons licence and your intended use is not permitted by statutory regulation or exceeds the permitted use, you will need to obtain permission directly from the copyright holder. To view a copy of this licence, visit http://creativecommons.org/licenses/by/4.0/.

\section{References}

Biasutti M, Voigt A, Boos WR et al (2018) Global energetics and local physics as drivers of past, present and future monsoons. Nat Geosci 11:392-400. https://doi.org/10.1038/s41561-018-0137-1

Broccoli AJ, Dahl KA, Stouffer RJ (2006) Response of the ITCZ to Northern Hemisphere cooling: ITCZ RESPONSE TO N. HEMISPHERE cooling. Geophys Res Lett 33:1. https://doi. org/10.1029/2005GL024546

Chen J, Chen F, Feng S et al (2015) Hydroclimatic changes in China and surroundings during the Medieval Climate Anomaly and Little Ice Age: spatial patterns and possible mechanisms. Quatern Sci Rev 107:98-111. https://doi.org/10.1016/j.quasc irev.2014.10.012

Chiang JCH, Bitz CM (2005) Influence of high latitude ice cover on the marine intertropical Convergence zone. Clim Dyn 25:477-496. https://doi.org/10.1007/s00382-005-0040-5

Chiang JCH, Friedman AR (2012) Extratropical cooling, interhemispheric thermal gradients, and tropical climate change. Annu Rev Earth Planet Sci 40:383-412. https://doi.org/10.1146/annur ev-earth-042711-105545

Collins M, Knutti R, Arblaster J, Dufresne JL, Fichefet T, Friedlingstein P, Shongwe M (2013) Long-term climate change: projections, commitments and irreversibility. In Climate Change 2013The Physical Science Basis: Contribution of Working Group I to the Fifth Assessment Report of the Intergovernmental Panel on Climate Change. Cambridge University Press.

Copernicus Climate Change Service (C3S) (2017) ERA5: Fifth generation of ECMWF atmospheric reanalyses of the global climate. Copernicus Climate Change Service Climate Data Store (CDS), date of access December, 2019. https://cds.climate.copernicus.eu/ cdsapp\#!/home

Deplazes G, Lückge A, Stuut J-BW et al (2014) Weakening and strengthening of the Indian monsoon during Heinrich events and Dansgaard-Oeschger oscillations: INDIAN MONSOON DURING HEINRICH EVENTS. Paleoceanography 29:99-114. https ://doi.org/10.1002/2013PA002509

Deser C, Tomas RA, Sun L (2015) The role of ocean-atmosphere coupling in the zonal-mean atmospheric response to Arctic sea ice loss. J Clim 28:2168-2186. https://doi.org/10.1175/JCLID-14-00325.1

Good P, Ingram W, Lambert FH et al (2012) A step-response approach for predicting and understanding non-linear precipitation changes. Clim Dyn 39:2789-2803. https://doi.org/10.1007/ s00382-012-1571-1

Hawkins E, Joshi M, Frame D (2014) Wetter then drier in some tropical areas. Nat Clim Chang 4:646-647. https://doi.org/10.1038/ nclimate2299

Herger N, Sanderson BM, Knutti R (2015) Improved pattern scaling approaches for the use in climate impact studies: IMPROVED PATTERN SCALING APPROACHES. Geophys Res Lett 42:3486-3494. https://doi.org/10.1002/2015GL063569

Kalnay E, Kanamitsu M, Kistler R, Collins W, Deaven D, Gandin L, Iredell M, Saha S, White G, Woolen J, Zhu Y, Chelliah M, 
Ebisuzaki W, Higgins W, Janowiak J, Mo KC, Ropelewski Wang J, Leetmaa A, Reynolds R, Jenne R, Joseph D (1996) The NCEP/ NCAR 40-year reanalysis project. Bull Am Meteorol Soc 77:437472. https://doi.org/10.1175/1520-0477(1996)077<0437:TNYRP $>2.0 . \mathrm{CO} ; 2$

Kang SM, Held IM, Frierson DMW, Zhao M (2008) The response of the ITCZ to extratropical thermal forcing: idealized slab-Ocean experiments with a GCM. J Clim 21:3521-3532. https://doi. org/10.1175/2007JCLI2146.1

Kim K-Y, Kim J, Boo K-O et al (2019) Intercomparison of precipitation datasets for summer precipitation characteristics over East Asia. Clim Dyn 52:3005-3022. https://doi.org/10.1007/s0038 2-018-4303-3

Kitoh A, Endo H, Krishna Kumar K et al (2013) Monsoons in a changing world: a regional perspective in a global context: GLOBAL MONSOONS IN CMIP5 MODELS. J Geophys Res Atmos 118:3053-3065. https://doi.org/10.1002/jgrd.50258

Kucharski F, Molteni F, Bracco A (2006) Decadal interactions between the western tropical Pacific and the North Atlantic Oscillation. Clim Dyn 26:79-91. https://doi.org/10.1007/s00382-005-0085-5

Kucharski F, Molteni F, King MP, Farneti R, Kang IS, Feudale L (2013) On the need of intermediate complexity general circulation models: a "SPEEDY" example. Bull Am Meteorol Soc 94(1):2530. https://doi.org/10.1175/BAMS-D-11-00238.1

Lee J-Y, Wang B (2014) Future change of global monsoon in the CMIP5. Clim Dyn 42(1-2):101-119

Li J, Cook ER, D’Arrigo R et al (2008) Common tree growth anomalies over the northeastern Tibetan Plateau during the last six centuries: implications for regional moisture change. Glob Change Biol 14:2096-2107. https://doi.org/10.1111/j.1365-2486.2008.01603.x

Liu Z, Otto-Bliesner BL, He F et al (2009) Transient simulation of last deglaciation with a new mechanism for B $\varnothing$ lling-Allerød warming. Science 325:26. https://doi.org/10.1126/science.1171041

Mohtadi M, Prange M, Steinke S (2016) Palaeoclimatic insights into forcing and response of monsoon rainfall. Nature 533:191-199. https://doi.org/10.1038/nature17450

Molteni F (2003) Atmospheric simulations using a GCM with simplified physical parametrizations. I: model climatology and variability in multi-decadal experiments. Clim Dyn 20:175-191. https:// doi.org/10.1007/s00382-002-0268-2

Monerie P, Robson J, Dong B et al (2019) Effect of the atlantic multidecadal variability on the global Monsoon. Geophys Res Lett 46:1765-1775. https://doi.org/10.1029/2018GL080903

Osborn TJ, Wallace CJ, Harris IC, Melvin TM (2016) Pattern scaling using ClimGen: monthly-resolution future climate scenarios including changes in the variability of precipitation. Clim Change 134:353-369. https://doi.org/10.1007/s10584-015-1509-9

Osborn TJ, Jones PD, Joshi M (2017) Recent United Kingdom and global temperature variations. Weather 72:323-329. https://doi. org/10.1002/wea.3174

Preisendorfer RW (1988) Principal component analysis in mete-orology and oceanography. In: Developments in atmospheric science, vol. 17. Elsevier, Amsterdam
Schneider T, Bischoff T, Haug GH (2014) Migrations and dynamics of the intertropical convergence zone. Nature 513:45-53. https:// doi.org/10.1038/nature13636

Seager R, Naik N, Vecchi GA (2010) Thermodynamic and dynamic mechanisms for large-scale changes in the hydrological cycle in response to global warming. J Clim 23:4651-4668. https://doi. org/10.1175/2010JCLI3655.1

Seager R, Osborn TJ, Kushnir Y, Simpson IR, Nakamura J, Liu H (2019) Climate variability and change of Mediterraneantype climates. J Clim 32:2887-2915. https://doi.org/10.1175/ JCLI-D-18-0472.1

Serreze MC, Barrett AP, Stroeve JC et al (2009) The emergence of surface-based Arctic amplification. Cryosphere 9

Seth A, Giannini A, Rojas M et al (2019) Monsoon Responses to Climate Changes-Connecting Past, Present and Future. Curr Clim Change Rep 5:63-79. https://doi.org/10.1007/s40641-019-00125 $-\mathrm{y}$

Talento S, Barreiro M (2016) Simulated sensitivity of the tropical climate to extratropical thermal forcing: tropical SSTs and African land surface. Clim Dyn 47:1091-1110. https://doi.org/10.1007/ s00382-015-2890-9

Trenberth KE, Guillemot CJ (1995) Evaluation of the global atmospheric moisture budget as seen from analyses. J Clim 8:2255-2272. https://doi.org/10.1175/1520-0442(1995)008<2255\%3AEOT $\mathrm{GAM}>2.0 . \mathrm{CO} \% 3 \mathrm{~B} 2$

Wang YJ (2001) A high-resolution absolute-dated Late pleistocene Monsoon record from Hulu Cave, China. Science 294:2345-2348. https://doi.org/10.1126/science.1064618

Wang Y, Cheng H, Edwards RL et al (2008) Millennial- and orbitalscale changes in the East Asian monsoon over the past 224,000 years. Nature 451:1090-1093. https://doi.org/10.1038/nature0669 2

Wang PX, Wang B, Cheng $\mathrm{H}$ et al (2017) The global monsoon across time scales: Mechanisms and outstanding issues. Earth Sci Rev 174:84-121. https://doi.org/10.1016/j.earscirev.2017.07.006

Yang B, Qin C, Wang J et al (2014) A 3500-year tree-ring record of annual precipitation on the northeastern Tibetan Plateau. Proc Natl Acad Sci 111:2903-2908. https://doi.org/10.1073/ pnas. 1319238111

Zhang R, Delworth TL (2005) Simulated tropical response to a substantial weakening of the Atlantic Thermohaline circulation. J Clim 18:1853-1860. https://doi.org/10.1175/JCLI3460.1

Publisher's Note Springer Nature remains neutral with regard to jurisdictional claims in published maps and institutional affiliations. 